\title{
Reactivity of Iridium Complexes of a Triphosphorus-Pincer Ligand Based on a Secondary Phosphine. Catalytic Alkane Dehydrogenation and the Origin of Extremely High Activity
}

Benjamin M. Gordon, Nicholas Lease, Thomas J. Emge, Faraj Hasanayn, Alan S. Goldman*

Department of Chemistry and Chemical Biology, Rutgers, The State University of New Jersey, Piscataway, New Jersey 08854, United States

\begin{abstract}
The selective functionalization of alkanes and alkyl groups is a major goal of chemical catalysis. Toward this end, a bulky triphosphine with a central secondary phosphino group, bis(2-di-t-butyl-phosphinophenyl)phosphine ( $\left.{ }^{\mathrm{tBu}} \mathrm{P}^{\mathrm{H}} \mathrm{PP}\right)$, has been synthesized. When complexed to iridium it adopts a meridional ("pincer") configuration. The secondary phosphino $\mathrm{H}$ atom can undergo migration to iridium to give an anionic phosphido-based-pincer ('BuPPP) complex. We describe novel metal-ligand cooperativity of the iridium-phosphido unit. Stoichiometric reactions of the ( ${ }^{\text {tBuPPP) }}$ Ir complexes reflect a distribution of steric bulk around the iridium center in which the coordination site trans to the phosphido group is quite crowded, one coordination site cis to the phosphido is even more crowded, while the remaining site is particularly open. The ('BuPPP)Ir precursors are the most active catalysts reported to date for dehydrogenation of $n$-alkanes, by about two orders of magnitude. The electronic properties of the iridium center are very similar to that of well-known analogous ( $\left.{ }^{\mathrm{P} P C P}\right)$ Ir catalysts. Accordingly, DFT calculations predict that ('BuPPP)Ir and ( ${ }^{\text {Bu }}$ PCP)Ir are, intrinsically, comparably active for alkane dehydrogenation. While dehydrogenation by $\left({ }^{R} P C P\right)$ Ir proceeds through an intermediate trans-(PCP) $\mid \mathrm{rH}_{2}$ (alkene), ( ${ }^{\text {(BuPPP }}$ )Ir follows a pathway proceeding via cis(PPP)I $\mathrm{rH}_{2}$ (alkene), thereby circumventing unfavorable placement of the alkene at the bulky site trans to phosphorus. ( $\left.{ }^{\mathrm{tBu} P P P}\right)$ Ir and ( $\left.{ }^{\mathrm{tBu}} \mathrm{PCP}\right) \mid \mathrm{r}$, however, have analogous resting states: square planar (pincer)Ir(alkene). Alkene coordination at the crowded trans site is therefore unavoidable in the resting states. Thus the resting state of the ( ${ }^{\text {tBuPPP }}$ ) Ir catalyst is destabilized by the unusual architecture of the ligand, and this is largely responsible for its unusually high catalytic activity.
\end{abstract}




\section{- INTRODUCTION}

Pincer ligands and metal-ligand cooperativity (MLC) represent two of the most active themes in the development of transition metal and main group metal chemistry and catalysis, and there has been substantial overlap between these areas of investigation. Numerous examples of pincer ligands engaging in novel catalytic and stoichiometric MLC-related reactions have been and continue to be reported. ${ }^{1-12}$ Yet despite the large number of pincer ligands for which MLC is based on a coordinating $\mathrm{N}$ atom, ${ }^{13-19}$ there are very few examples involving the next congener, phosphorus. In particular, in spite of the great value that has been proven for addition of $\mathrm{H}_{2}$ across $\mathrm{M}-\mathrm{N}$ bonds, there are relatively few examples of $\mathrm{H}_{2}$ addition across a phosphorus metal bond, ${ }^{20-25}$ and even fewer examples of the reverse, elimination of $\mathrm{H}_{2}{ }^{25-26}$

Phosphorus has been referred to as "the carbon copy" ${ }^{27}$ because of numerous similarities between the chemistry, including the coordination chemistry, of these elements. PCP-type pincer ligands, in which the coordinating atom of the central group is typically a formally anionic carbon, have played an important role in organometallic chemistry in recent decades. An example of this of particular interest in our laboratory has been the chemistry of (PCP)Ir complexes as catalysts for alkane dehydrogenation. ${ }^{28-40}$ In the context of this relationship, and in combination with the potential for an anionic phosphido group to engage in MLC behavior, we have begun an investigation of (PPP)Ir complexes in which the central group is formally anionic phosphido. ${ }^{41-51}$

Scheme 1. Pincer ligands of the type used in this work
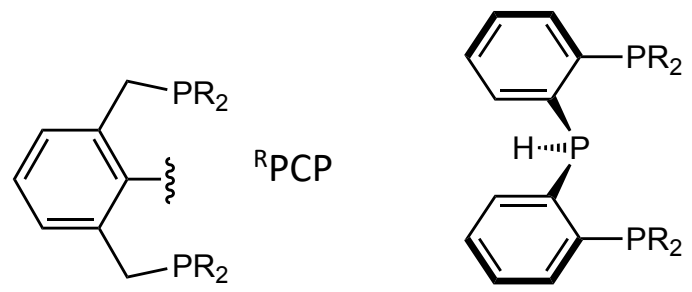

${ }^{\mathrm{R} P}{ }^{\mathrm{H}} \mathrm{PP} \quad \mathrm{R}={ }^{i} \mathrm{Pr}^{45-48}, \mathrm{Ph}^{48-51},{ }^{t} \mathrm{Bu}$ (this work)

In order to enforce a rigid meridional coordination geometry, ${ }^{49,51}$ to prevent cluster formation, ${ }^{45}$ and to best explore the relationship with (PCP)Ir chemistry, we chose to investigate a system amenable to comparison with ( $\left.{ }^{\mathrm{B} u P C P}\right) \operatorname{Ir}\left({ }^{\mathrm{R}} \mathrm{PCP}=\kappa^{3}-2,6-\mathrm{C}_{6} \mathrm{H}_{3}\left(\mathrm{CH}_{2} \mathrm{PR}_{2}\right)_{2}\right)$, the chemistry of which has been characterized in depth. ${ }^{34,52}$ To this end, we have synthesized bis(2-di-t-butyl-phosphinophenyl)phosphine ('BupHPP; Scheme 1), the bulky analogue of previously reported triphosphorus proligands ${ }^{\text {PrP }}{ }^{H} P P$ and ${ }^{P h}{ }^{H}{ }^{H} P P .45,49-51$ Iridium complexes of ${ }^{\text {tBu}}{ }^{H} \mathrm{PP}$ and the corresponding phosphido ( ${ }^{\mathrm{Bu}} \mathrm{PPP}$ ) derivatives were synthesized and their stoichiometric and catalytic chemistry investigated.

We report herein unusual fundamental chemistry of this ligand-metal fragment, including the first examples of reversible addition of $\mathrm{H}_{2}$ across the M-P bond of a metal phosphido unit. 
Importantly, the ( $\left.{ }^{\text {tBu}} \mathrm{PPP}\right)$ Ir unit investigated is not approximately planar like ( $\left.{ }^{\mathrm{R}} \mathrm{PCP}\right)$ Ir, nor even approximately symmetrical as typically found with complexes of the isostructural diarylaminebased PNP ligands developed by Ozerov. ${ }^{53-54}$ Instead, the pyramidal geometry of the central phosphorus atom results in a bowl-like ligand structure, analogous to the geometry we have recently reported ${ }^{55}$ for a (PSP)Ru complex. This in turn results in a highly unsymmetrical positioning of the phosphino-t-butyl groups in which one face of the complex is fairly open while the coordination site trans to the central coordinating P atom is very crowded. This is clearly manifest in the addition and elimination of small molecules including $\mathrm{H}_{2}, \mathrm{D}_{2}$, and $\mathrm{CO}$. This architectural motif is found to be particularly advantageous for the catalytic dehydrogenation of $n$-alkanes to give 1-alkenes. We report that the ( ${ }^{\text {tBuPPP}}$ )Ir fragment is by far the most highly active catalyst for alkane transfer-dehydrogenation developed to date, and affords high regioselectivity; we attribute these properties in large part to this unsymmetrical spatial configuration.

\section{- RESULTS AND DISCUSSION}

Synthesis of ${ }^{\text {tBupH}}{ }^{H}$ PP and Metalation. (2-bromophenyl)-di-tert-butylphosphine was synthesized according to Shimada. ${ }^{56}$ Coupling with $\mathrm{PCl}_{3}$ to give $\left(2-\mathrm{C}_{6} \mathrm{H}_{4} \mathrm{P}^{t} \mathrm{Bu}_{2}\right)_{2} \mathrm{PCl}$ and reduction to give ${ }^{\mathrm{tBu}} \mathrm{P} \mathrm{HP}$ was then conducted as reported by Peters. ${ }^{45} \mathrm{~A}$ characteristic resonance expected of the secondary phosphine proton was observed in the ${ }^{1} \mathrm{H} N M R$ spectrum $(\delta 6.03, d t$, $\mathrm{J}=214.8,12.3 \mathrm{~Hz}$ ) while in the ${ }^{31} \mathrm{P}\left\{{ }^{1} \mathrm{H}\right\}$ NMR spectrum a doublet $(\delta 21.35)$ and a triplet $(\delta-47.07)$ were observed with ${ }^{3} \mathrm{JP}=154 \mathrm{~Hz}$.

Dissolving ${ }^{\mathrm{tBu}} \mathrm{P}^{\mathrm{H} P P}$ in a toluene solution with either $[\operatorname{Ir}(\mathrm{COD}) \mathrm{Cl}]_{2}$ or $\left.\operatorname{Ir}(\mathrm{COE})_{2} \mathrm{Cl}\right]_{2}$ rapidly yields free cyclooctadiene or cyclooctene, respectively, and ( $\left.{ }^{\mathrm{Bu} u}{ }^{\mathrm{H} P P}\right) \mathrm{IrCl}$ (Scheme 2), with signals in the ${ }^{31} \mathrm{P}\left\{{ }^{1} \mathrm{H}\right\}$ NMR spectrum at $\delta 76.5(\mathrm{~d}, \mathrm{~J}=12.8 \mathrm{~Hz})$ and $\delta 26.3(\mathrm{t}, \mathrm{J}=12.8 \mathrm{~Hz}) .{ }^{57}$ Thus, metalation is accompanied by a dramatic decrease in the value of $J_{\mathrm{PP}}$, indicative of $\kappa^{3}$-coordination of a triphosphorus ligand. ${ }^{57}$ The ${ }^{1} \mathrm{H}$ NMR resonance of the phosphine-bound proton shifts upfield to $\delta 4.60$, while ${ }^{1} \mathrm{~J}_{\mathrm{PH}}$ increases to $365 \mathrm{~Hz}\left({ }^{3} \mathrm{~J}_{\mathrm{P}-\mathrm{H}}=2.7 \mathrm{~Hz}\right)$.

\section{Scheme 2. Metalation of ( $\left.{ }^{\mathrm{tBu}}{ }^{\mathrm{H}} \mathrm{PP}\right)$ and Proton Transfer}

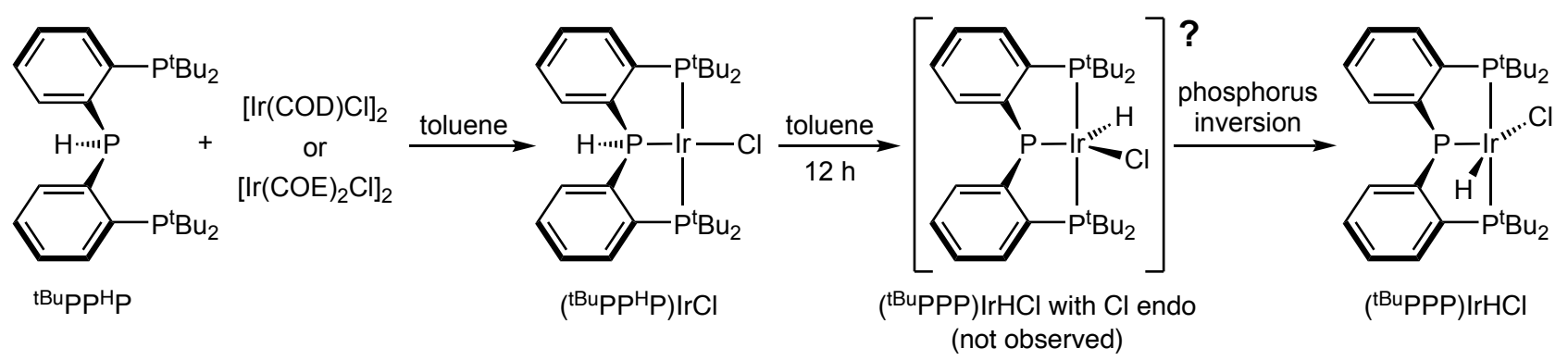


Formation of four-coordinate ( $\left.{ }^{\mathrm{tBu}} \mathrm{P}^{\mathrm{H}} \mathrm{PP}\right) \mathrm{IrCl}$ is followed by slow net proton transfer to yield ('BuPPP) IrHCl (Scheme 2), as monitored in the ${ }^{1} \mathrm{H}$ NMR spectrum by loss of the signal at $\delta 4.60$ and concomitant appearance of a new hydride signal $(\delta-28.0, \mathrm{td}, \mathrm{J}=13.2,7.3 \mathrm{~Hz}) .{ }^{58} \mathrm{In}$ the ${ }^{31} \mathrm{P}\left\{{ }^{1} \mathrm{H}\right\}$ NMR spectrum, the resonance corresponding to the central phosphorus $(\delta 26.3, \mathrm{t}, \mathrm{J}=$ $12.8)$ shifts $70 \mathrm{ppm}$ downfield $(\delta 97.2, \mathrm{~s})$ while the terminal phosphine resonance shifts only from $\delta 76.5$ to $\delta$ 76.3. A crystal suitable for X-ray diffractometry was obtained by vapor diffusion of pentane into a saturated toluene solution and the molecular structure was determined by X-ray diffraction (XRD) (Figure 1). The unit cell is found to contain two molecules of ( ${ }^{\text {tBuPPP}}$ ) IrHCl where the only notable difference between them is between the $\mathrm{P}_{\mathrm{c}}-\mathrm{Ir}-\mathrm{Cl}$ bond ( $P_{c}=$ central phosphorus) angles. In one molecule, the angle is $124.0^{\circ}$, suggesting a nearly ideal trigonal bipyramidal geometry while in the other it is $144.5^{\circ}$. These values are both in contrast with the $\mathrm{C}_{\mathrm{ipso}}-\mathrm{Ir}-\mathrm{Cl}$ bond angles, which are very nearly $180^{\circ}$, found for the square-pyramidal geometries of iridium hydrido chloride complexes of PCP-type ligands ${ }^{59-61}$. The sum of angles around the central (phosphido) phosphorus atom of ( $\left.{ }^{\mathrm{B} u P P P}\right) \mathrm{IrHCl}$ is $321.1^{\circ}$, indicating a fully pyramidal geometry. Lastly we note that the chloride is located exo with respect to the bowlshaped PPP ligand structure. While this might be expected to be thermodynamically favored due to steric crowding, an intramolecular proton transfer from ( $\left.{ }^{\text {tBup }}{ }^{\mathrm{H} P P}\right) \mid \mathrm{rCl}$ would be expected to lead directly to the endo-chloride configuration (Scheme 2); this could then be followed by inversion at $\mathrm{P}_{\mathrm{C}}$ to give the observed product.

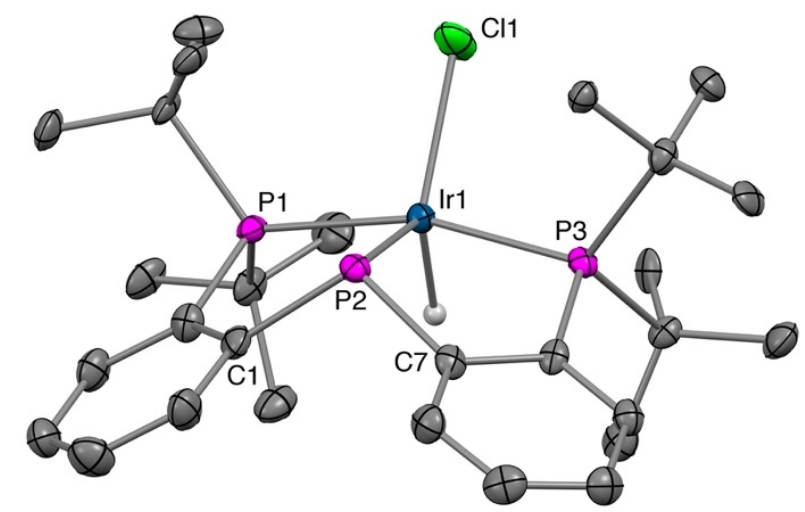

Figure 1. Molecular structure of one of the two molecules of ('BuPPP)IrHCl determined by singlecrystal XRD. $\mathrm{H}$ atoms other than the hydride are omitted for clarity. Thermal ellipsoids are shown at 50\% probability. Selected distances $(\AA ̊)$ and angles ( $\left.{ }^{\circ}\right)$ : P2-Ir1, 2.211(4); P1-Ir1 2.357(4); P3-Ir1, 2.339(4); Cl1-Ir1, 2.379(4); P2-Ir1-Cl1, 124.42(16); P1-Ir1-Cl1, 98.60(15); P3-Ir1Cl1, 99.12(15); P1-Ir1-P3, 162.04(14); P1-Ir1-P2, 86.52(14); P3-Ir1-P2, 85.94(15); C1-P2-Ir1, 106.2(5); C7-P2-Ir1, 107.0(5); C7-P2-C1, 107.6(5) 


\section{Scheme 3. Synthesis of ( $\left.{ }^{\mathrm{tBu}} \mathrm{P}^{\mathrm{H}} \mathrm{PP}\right) \mathrm{IrH}_{3}$}

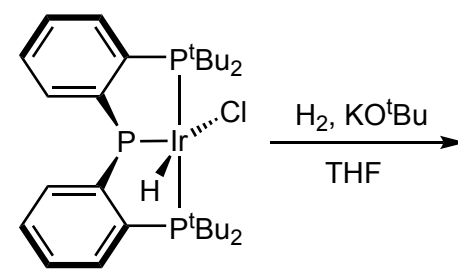

('BuPPP) IrHCl

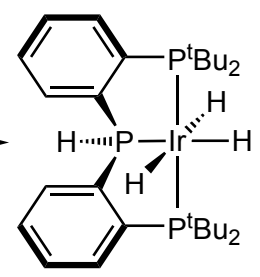

( $\left.{ }^{\mathrm{BBu}} \mathrm{P}^{\mathrm{H}} \mathrm{PP}\right) \mathrm{IrH}_{3}$

Treatment of ( $\left.{ }^{\mathrm{tBu}} \mathrm{PPP}\right) \mathrm{IrHCl}$ with $\mathrm{KO}^{\mathrm{t}} \mathrm{Bu}$ under an atmosphere of $\mathrm{H}_{2}$ in THF rapidly leads to the formation of a complex with a secondary phosphine at the central position, as indicated by an upfield resonance in the ${ }^{31} \mathrm{P}$ NMR spectrum $(\delta 10.7)$ and a signal in the ${ }^{1} \mathrm{H}$ NMR spectrum at $\delta$ 5.71 with coupling ${ }^{1} \mathrm{~J}_{\mathrm{PH}}=335.5 \mathrm{~Hz}$, assigned as ( $\left.{ }^{\mathrm{tBu}} \mathrm{P}^{\mathrm{H} P P}\right) \mid \mathrm{rH}_{3}$ (Scheme 3 ). The three hydrides are chemically inequivalent due to the unsymmetrical nature of the ligand and they exhibit complex coupling patterns in the ${ }^{1} \mathrm{H}$ NMR spectrum. The formation of ( $\left.{ }^{\mathrm{tBu}} \mathrm{P}^{\mathrm{H} P P}\right) \mid \mathrm{rH} \mathrm{H}_{3}$ involves a net heterolytic cleavage of the dihydrogen bond across the P-Ir bond.

2D ${ }^{1} \mathrm{H}$-NOESY-NMR spectroscopy was used to assign the individual hydride resonances. Crystals were obtained through slow evaporation of benzene, and the molecular structure was determined by single-crystal XRD (Figure 2).

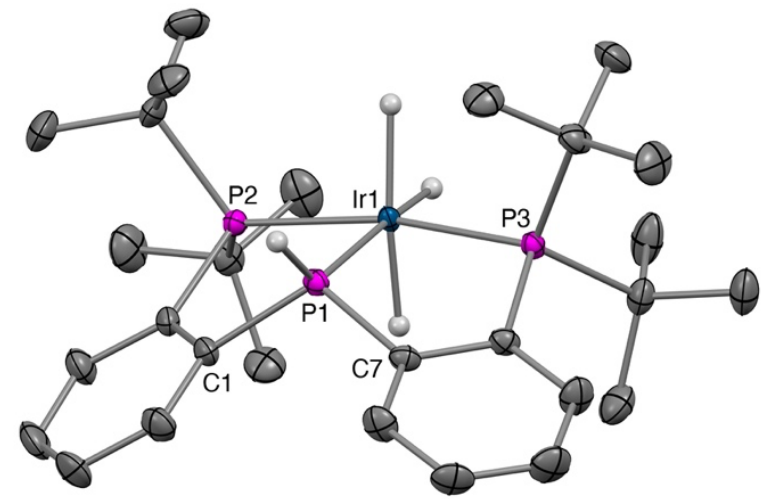

Figure 2. Molecular structure of ( $\left.{ }^{\mathrm{tBu}} \mathrm{P}^{\mathrm{H} P P}\right) \mid \mathrm{rH}_{3}$ determined by single-crystal XRD. $\mathrm{H}$ atoms other than the hydrides and the central phosphino hydrogen are omitted for clarity. Thermal ellipsoids are shown at 50\% probability. Selected distances ( $\AA$ ) and angles $\left({ }^{\circ}\right)$ : P1-Ir1, 2.2311(8); P2-Ir1, 2.2786(9); P3-Ir1, 2.2880(9); P1-Ir1-P3, 84.78(3); P1-Ir1-P2, 85.28(3); P2-Ir1-P3, 167.79(3); C1-P1-C7, 113.39(14); C1-P1-Ir1, 107.66(10); C7-P1-Ir1, 109.62(10)

Stoichiometric Reactions of ( $\left.{ }^{\text {tBupH}} \mathrm{HP}\right)$ Ir and ( $\left.{ }^{\mathrm{tBu}} \mathrm{PPP}\right)$ Ir Complexes: Experimental Studies. A toluene- $\mathrm{d}_{8}$ solution of ( $\left.{ }^{\mathrm{BBu}} \mathrm{PH}^{\mathrm{H} P}\right) \mid \mathrm{rH}_{3}$ was heated at $80^{\circ} \mathrm{C}$ under 1 atm ethylene for $15 \mathrm{~min}$, leading the straw-yellow solution to turn dark green. NMR spectroscopy indicated loss of $\left({ }^{\mathrm{BB}} \mathrm{P}^{\mathrm{H}} \mathrm{PP}\right) \mathrm{IrH} \mathrm{H}_{3}$ and formation of ( $\left.{ }^{\mathrm{tBu}} \mathrm{PPP}\right) \operatorname{Ir}\left(\mathrm{C}_{2} \mathrm{H}_{4}\right)$, evidenced by a significant downfield shift in the signal assigned to $\mathrm{P}_{\mathrm{C}}\left({ }^{31} \mathrm{P}\right.$ NMR; $\left.\delta 155.48\right)$ as well as the presence of a peak corresponding to 
bound ethylene in the ${ }^{1} \mathrm{H} N M R$ spectrum $\left(\delta 3.57,4 \mathrm{H}\right.$, at $\left.0^{\circ} \mathrm{C}\right)$. The $t$-butyl groups of $\left({ }^{\mathrm{B} u} \mathrm{PPP}\right) \operatorname{Ir}\left(\mathrm{C}_{2} \mathrm{H}_{4}\right)$ are equivalent on the NMR timescale at all temperatures at which spectra were taken $\left(-90^{\circ} \mathrm{C}\right.$ to $\left.110^{\circ} \mathrm{C}\right)$, suggesting rapid inversion of the phosphide group. ${ }^{62-63}$ The ${ }^{1} \mathrm{H}$ NMR spectrum also revealed formation of 2 equivalents of ethane.

In contrast with ( $\left.{ }^{\text {tBuPCP}}\right) \operatorname{Ir}\left(\mathrm{C}_{2} \mathrm{H}_{4}\right)$ and ( $\left.{ }^{\mathrm{BBu}} \mathrm{POCOP}\right) \operatorname{Ir}\left(\mathrm{C}_{2} \mathrm{H}_{4}\right),{ }^{64}\left({ }^{\mathrm{tBu}} \mathrm{PPP}\right) \operatorname{Ir}\left(\mathrm{C}_{2} \mathrm{H}_{4}\right)$ decomposes upon removal of the ethylene atmosphere as manifest by color change and loss of ${ }^{1} \mathrm{H}$ and ${ }^{31} \mathrm{P} N M R$ signals. ${ }^{1} \mathrm{H}$ NMR spectra, taken from $25^{\circ} \mathrm{C}$ to $110{ }^{\circ} \mathrm{C}$ in $p$-xylene- $\mathrm{d}_{10}$ solvent, reveal sharp signals at the low end of this range. Broadening of free and bound $\mathrm{C}_{2} \mathrm{H}_{4}$ signals is observed at $40{ }^{\circ} \mathrm{C}$ and above, indicating exchange on the NMR time scale. The signals attributable to free and bound $\mathrm{C}_{2} \mathrm{H}_{4}$ undergo coalescence at $110^{\circ} \mathrm{C}$. Exchange rates were determined, based on line broadening, from $50^{\circ} \mathrm{C}$ to $80^{\circ} \mathrm{C}$. An Eyring-type plot of this data (Figure S2) yields activation parameters $\Delta H^{*}=19.8( \pm 0.7) \mathrm{kcal} / \mathrm{mol}$ and $\Delta S^{\ddagger}=9.3( \pm 2)$ eu, consistent with a weakly bound ethylene ligand undergoing rapid reversible dissociation. The analogous propene complex showed an even lower barrier to exchange with free propene; coalescence was reached for the three vinylic protons in the ${ }^{1} \mathrm{H}$ NMR spectrum in the range $10^{\circ} \mathrm{C}$ to $40{ }^{\circ} \mathrm{C}$. Due to the complexity of the spectra, the confidence level in the rate determinations is lower than for ethylene, but the values obtained for propene exchange, $\Delta \mathrm{H}^{+}=17.9 \mathrm{kcal} / \mathrm{mol}$ and $\Delta \mathrm{S}^{\ddagger}=18 \mathrm{eu}$, clearly indicate a dissociative process. The corresponding value of $\Delta \mathrm{G}^{\ddagger}=12.5 \mathrm{kcal} / \mathrm{mol}$ at $298 \mathrm{~K} \mathrm{implies}$ that propene is bound ca. 4 - $5 \mathrm{kcal} / \mathrm{mol}$ even more weakly than ethylene $\left(\Delta \mathrm{G}^{*}=17.0( \pm 1.0) \mathrm{kcal} / \mathrm{mol}\right.$ at $298 \mathrm{~K})$.

The instability of ( $\left.{ }^{\mathrm{Bu}} \mathrm{PCP}\right) \operatorname{Ir}\left(\mathrm{C}_{2} \mathrm{H}_{4}\right)$ precluded its crystallization. Replacement of ethylene with a $\mathrm{CO}$ atmosphere resulted in conversion of ( $\left.{ }^{\mathrm{tBu} P P P}\right) \operatorname{Ir}\left(\mathrm{C}_{2} \mathrm{H}_{4}\right)$ to $\left({ }^{\mathrm{tBu} P P P}\right) \operatorname{Ir}(\mathrm{CO})$, which represents the first fully characterized four-coordinate terminal-phosphido iridium complex. The C-O stretching frequency of ( ${ }^{\text {Bu }}$ PPP) Ir(CO) in benzene observed in the IR spectrum is $1922 \mathrm{~cm}^{-1}$. This value is very similar to that reported for ( $\left.{ }^{\mathrm{Bu}} \mathrm{PCP}\right) \operatorname{Ir}(\mathrm{CO})^{65}$ (in $n$-hexane), $1914 \mathrm{~cm}^{-1}, 60$ indicating that the iridium centers of these complexes have similar electronic properties. Crystallization of ('BuPPP) Ir(CO) was successful, and XRD analysis yielded a structure (Figure 3 ) with a unit cell containing two molecules. The sums of the angles around the terminal phosphide are $327.8^{\circ}$ and $328.6^{\circ}$, respectively, i.e. both molecules have a fully pyramidal geometry at $P$. The angles between the $\mathrm{CO}$ and terminal phosphide $(\angle \mathrm{P}-\mathrm{Ir}-\mathrm{C})$ are ca. $164^{\circ}$. This deviation from $180^{\circ}$ was probed computationally and shown to be a result of the steric influence of the tert-butyl groups (Figure S50). ${ }^{66}$ 
(a)

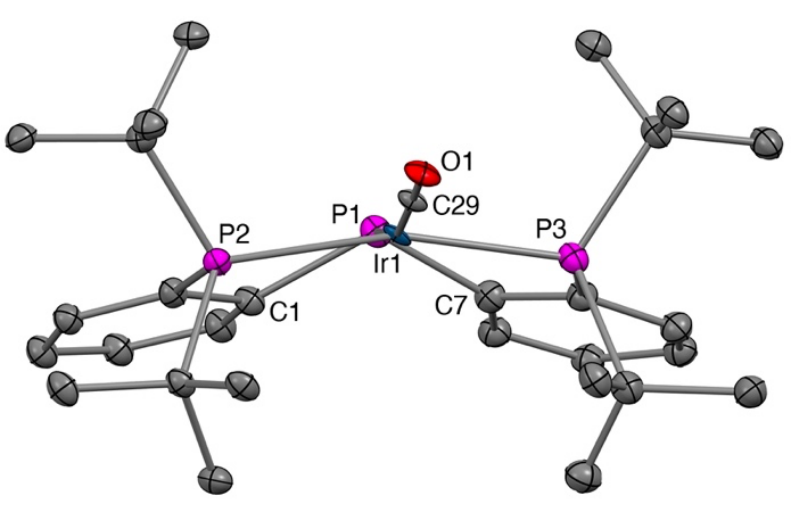

(b)

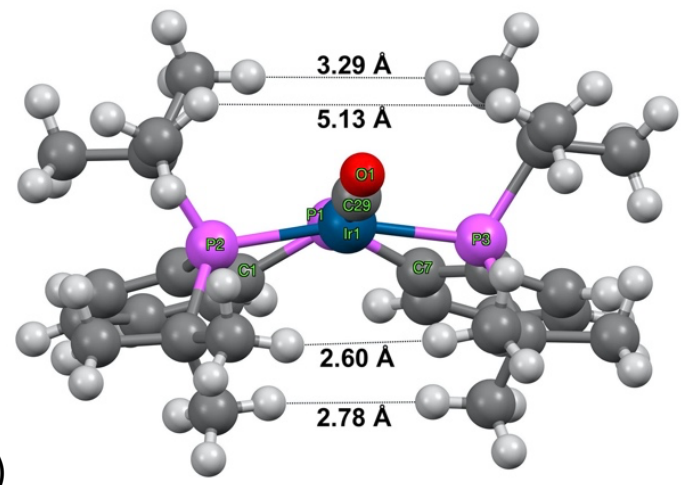

Figure 3. (a) Molecular structure of ('BuPPP) Ir(CO) determined by single-crystal XRD. $\mathrm{H}$ atoms omitted for clarity. Thermal ellipsoids are shown at $50 \%$ probability. Selected distances ( $\AA$ ) and angles ( ${ }^{\circ}$ ): P1-Ir1, 2.289(3); P2-Ir1, 2.304(3); P3-Ir1, 2.317(3); Ir1-C29, 1.869(11); C29-O1, 1.149(14); P1-Ir1-P2, 83.86(10); P1-Ir1-P3, 83.89(10); P1-Ir1-C29, 166.0(4); P2-Ir1-P3, 160.04(10); C1-P1-C7, 113.3(6); C1-P1-Ir1, 109.5(4); C7-P1-Ir1, 109.2(4). (b) Ball-and-stick style illustration of the same structure, $\mathrm{H}$ atoms included, highlighting the difference in crowding between the faces above and below the approximate plane of the iridium and coordinating atoms.

We wished to better understand the mechanism of ethylene hydrogenation by ( $\left.{ }^{\mathrm{BBu}} \mathrm{P} \mathrm{HPP}\right) \mid \mathrm{rH} \mathrm{H}_{3}$, and particularly the loss and apparent net transfer of the phosphorus-bound hydrogen. Charging a solution of ( $\left.{ }^{\mathrm{BBu}} \mathrm{PH} P \mathrm{PP}\right) \mathrm{Ir} \mathrm{H}_{3}$ with $1 \mathrm{~atm}$ of $\mathrm{D}_{2}$ led to a rapid and highly selective loss of signals corresponding to the exo and trans hydrides. Signals attributable to the phosphorus-bound proton and the endo-hydride maintained their integration relative to the aromatic peaks of the complex. This result indicates a remarkably stereoselective loss of $\mathrm{H}_{2}$ (Scheme 4), exclusively from the exo face of the complex. Also consistent with loss of $\mathrm{H}_{2}$ occurring exclusively from the exo face, $\left({ }^{\mathrm{BB} u P H} \mathrm{PP}\right) \mid \mathrm{rH} \mathrm{H}_{3}$ and the labelled $\left({ }^{\mathrm{tBu}} \mathrm{P} \mathrm{H} P \mathrm{PP}\right) \operatorname{Ir}(\mathrm{D})_{2}($ endo-H) both yielded exclusively ( $\left.{ }^{\mathrm{BBu}} \mathrm{P} \mathrm{HPP}\right) \operatorname{Ir}($ exo-CO)(H) when treated with $1 \mathrm{~atm}$ of $\mathrm{CO}$ (Scheme 4).

\section{Scheme 4. Stereoselective displacement of $\mathrm{H}_{2}$ from ( $\left.{ }^{\mathrm{tBu} P \mathrm{HPP}}\right) \mid \mathrm{rH}_{3}$}

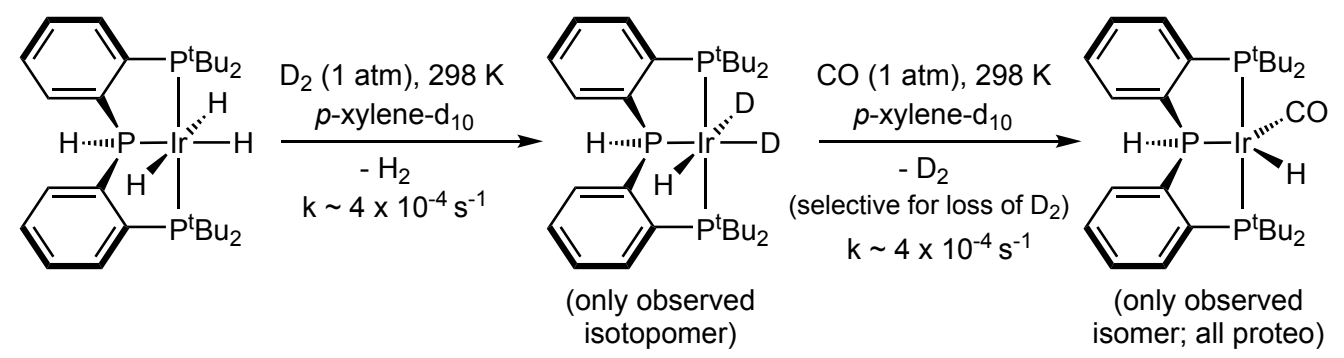

The obvious mechanistic pathways for both the isotopic substitution and the displacement

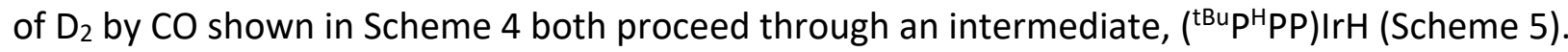
With that in mind, one equivalent of hydrogen acceptor ( $t$-butyl ethylene, TBE; or norbornene, NBE) was added to a solution of ( $\left.{ }^{(B u p H P P}\right) \mid \mathrm{rH}_{3}$. After $24 \mathrm{~h}$ at room temperature a dark red 
solution had formed and NMR spectroscopy indicated conversion to a new species, assigned as ( $\left.{ }^{\mathrm{tBu}} \mathrm{PH} \mathrm{PP}\right) \mathrm{IrH}$. This is a rare example of a square planar iridium monohydride. ${ }^{67-69}$ The ${ }^{31} \mathrm{P}\left\{{ }^{1} \mathrm{H}\right\}$ NMR spectrum has signals at $\delta 102.43\left(\mathrm{~d}, J_{\mathrm{PP}}=10 \mathrm{~Hz}\right)$ and $\delta 37.01\left(\mathrm{t}, J_{\mathrm{PP}}=10 \mathrm{~Hz}\right)$ in a 2:1 ratio. The phosphorus-bound proton is clearly observed in the ${ }^{1} \mathrm{H}$ NMR spectrum $\left(\delta 4.56, \mathrm{~d}^{1}{ }^{1} \mathrm{~J}_{\mathrm{PH}}=\right.$ 320.9), and other signals are unexceptional. Remarkably, however, the hydride of ( $\left.{ }^{\mathrm{B} u P H} \mathrm{PP}\right) \mathrm{IrH}$ gives rise to a very downfield chemical shift in the ${ }^{1} \mathrm{H}$ NMR spectrum $(\delta 4.70, \mathrm{dt}, \mathrm{J}=112.9,18.3$ $\mathrm{Hz}){ }^{70}$ Selective ${ }^{31} \mathrm{P}$-decoupling confirmed that the coupling of $112.9 \mathrm{~Hz}$ was with the central $\mathrm{P}$ atom ( $\delta 102.43$ ) and the coupling of $18.3 \mathrm{~Hz}$ with the terminal pincer $P$ atoms ( $\delta 37.01$ ) (Figure S31). ${ }^{66}$

Scheme 5. Reactions of ( $\left.{ }^{\mathrm{tBu}}{ }^{\mathrm{H}} \mathrm{PP}\right) \mid \mathrm{rH}$, ( $\left.{ }^{\mathrm{BBu} P P P}\right) \mid \mathrm{rH}_{2}$, and ( $\left.{ }^{\mathrm{tBu}} \mathrm{P}^{\mathrm{H}} \mathrm{PP}\right) \mid \mathrm{rH}_{3}$

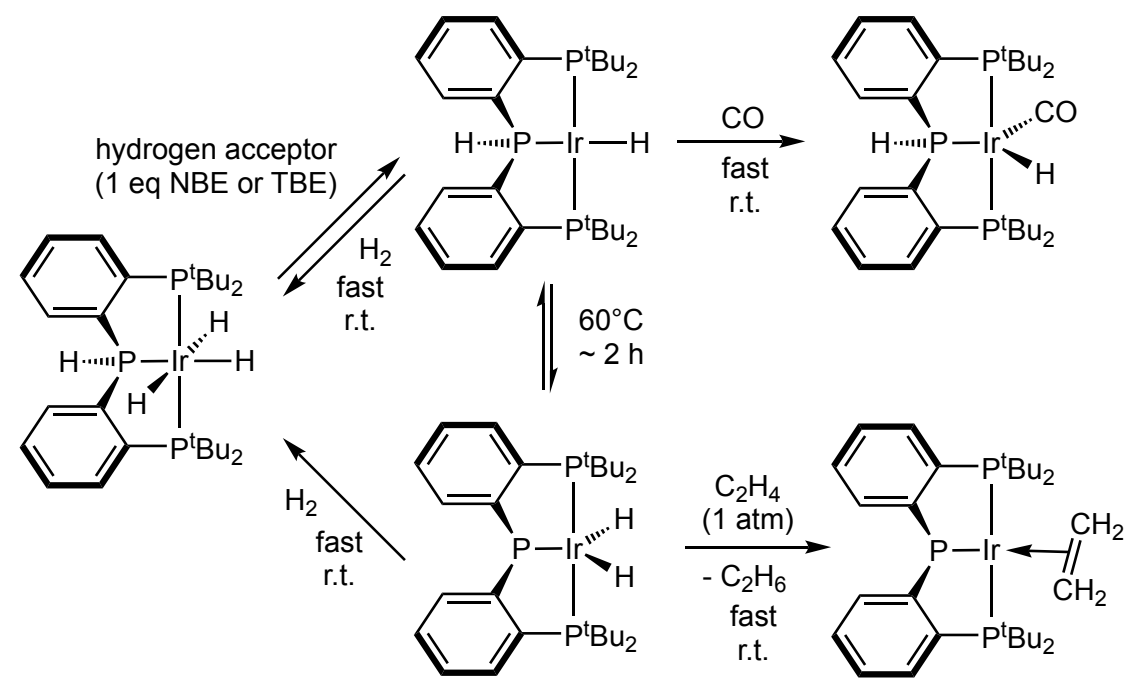

While relatively common for $d^{0}$ and $d^{10}$ metal hydrides, ${ }^{71-73}$ such downfield chemical shifts are highly unusual, although not completely unprecedented ${ }^{74-76}$, for other transition metal hydrides. Variable temperature ${ }^{1} \mathrm{H} N M R$ was performed $\left(10-60^{\circ} \mathrm{C}\right)$ and the chemical shift attributable to the hydride was found to be moderately temperature sensitive; however the signals were sharp at all temperatures, indicating that this is not a dynamic NMR phenomena, i.e. due to rapid exchange with a chemically different site (Figure S32) ${ }^{66}$ The origin of this unusual chemical shift is currently under investigation. ${ }^{77}$

Placing a solution of ( ${ }^{\mathrm{tBu}} \mathrm{PH}^{\mathrm{H}} \mathrm{PP}$ ) IrH under $1 \mathrm{~atm}$ of $\mathrm{CO}$ led to immediate conversion to ( $\left.{ }^{\mathrm{tBu}}{ }^{\mathrm{H}} \mathrm{PP}\right) \mathrm{Ir}(\mathrm{H}) \mathrm{CO}$ (Scheme 5), the same complex that only slowly formed upon the addition of $\mathrm{CO}$ to ( $\left.{ }^{\mathrm{tBu}} \mathrm{PH} \mathrm{PP}\right) \mathrm{IrH}_{3}$ (Scheme 4). The much faster reaction of the monohydride is consistent with its proposed role as an intermediate in the reaction of the trihydride.

Heating ( $\left.{ }^{\mathrm{tBu}} \mathrm{PH}^{\mathrm{H}} \mathrm{PP}\right) \mathrm{IrH}$ at $60^{\circ} \mathrm{C}$ for $2 \mathrm{~h}$ results in formation of a new complex, with partial loss of signal attributable to the P-bound $\mathrm{H}$ and the downfield hydride signal in the ${ }^{1} \mathrm{H} N M R$ spectrum. Concomitantly, a new upfield signal appears $(\delta-19.40, \mathrm{dt}, J=56.6,11.4 \mathrm{~Hz}, 2 \mathrm{H})$, which we assign to the formation of ( $\left.{ }^{\mathrm{tBu} P P P}\right) \mid \mathrm{rH}_{2}$ (Scheme 5). ( $\left.{ }^{\mathrm{tBu}}{ }^{\mathrm{H} P P}\right) \mid \mathrm{rH}$ and ( $\left.{ }^{\mathrm{tBu}} \mathrm{PPP}\right) \mid \mathrm{rH} \mathrm{H}_{2}$ exist 
in equilibrium in a ratio of $\sim 1: 2 .{ }^{69,78}$ As observed with ( $\left.{ }^{\mathrm{tBu} P P P}\right) \operatorname{Ir}(\mathrm{CO})$ and $\left({ }^{\mathrm{tBu} P P P}\right) \operatorname{Ir}\left(\mathrm{C}_{2} \mathrm{H}_{4}\right)$, the $t$ butyl groups of ( ${ }^{\text {BBuPPP) }}$ IrH $\mathrm{H}_{2}$ appear equivalent in the ${ }^{1} \mathrm{H}$ NMR spectrum.

Addition of $1 \mathrm{~atm}$ of ethylene to a room-temperature solution containing a mixture of

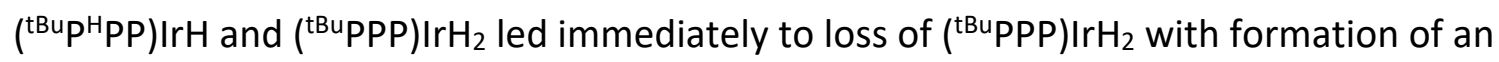
equivalent quantity of ( $\left.{ }^{\mathrm{BB} u P P P}\right) \operatorname{Ir}\left(\mathrm{C}_{2} \mathrm{H}_{4}\right)$ while the concentration of ( $\left.{ }^{\mathrm{tBu}}{ }^{\mathrm{H} P P}\right)$ ) $\mathrm{rH}$ was initially unchanged. Thus the five-coordinate $d^{6}$ complex ( $\left.{ }^{\mathrm{tBu}} \mathrm{PPP}\right) \mid \mathrm{rH}_{2}$ reacts much more rapidly with ethylene (to give ethane and an ethylene complex) than does the four-coordinate $d^{8}$ $\left({ }^{\mathrm{BBu}} \mathrm{P}^{\mathrm{H}} \mathrm{PP}\right) \mathrm{IrH}$. Upon heating the resulting mixture for $2 \mathrm{~h}$ at $60^{\circ} \mathrm{C}$, however, full conversion to ('BuPPP) $\operatorname{Ir}\left(\mathrm{C}_{2} \mathrm{H}_{4}\right)$ was observed (Scheme 5).

Addition of $1 \mathrm{~atm}$ of $\mathrm{H}_{2}$ to a solution of ( $\left.{ }^{\mathrm{tBu}}{ }^{\mathrm{H}} \mathrm{PP}\right) \mathrm{IrH}$ and ( $\left.{ }^{\mathrm{BB} u P P P}\right) \mid \mathrm{rH}_{2}$ at room temperature led to the immediate formation of ( $\left.{ }^{\mathrm{Bu}} \mathrm{P}^{\mathrm{H}} \mathrm{PP}\right) \mathrm{IrH}_{3}$, representing a rapid net addition across a metal-phosphorus bond in the case of addition to the dihydride (Scheme 5).

Stoichiometric Reactions of ( ${ }^{\text {Bu }}{ }^{H}$ PP) Ir and ( ${ }^{\text {Bu }}$ PPP) Ir Complexes: DFT Calculations. The relationship between ( $\left.{ }^{\mathrm{tBu}} \mathrm{P}^{\mathrm{H}} \mathrm{PP}\right) \mathrm{IrH} \mathrm{rH}_{3},\left({ }^{\mathrm{tBu}} \mathrm{P}^{\mathrm{H}} \mathrm{PP}\right) \mathrm{IrH}$, and ( $\left.{ }^{\mathrm{tBu} P P P}\right) \mid \mathrm{rH}_{2}$ was investigated computationally (Figure 4). Starting from ( $\left.{ }^{\left.\mathrm{tBu} \mathrm{P}^{\mathrm{H}} \mathrm{PP}\right)}\right) \mathrm{rH}_{3}$, there is a calculated barrier of $\Delta \mathrm{G}^{\ddagger}=16.7$ $\mathrm{kcal} / \mathrm{mol}$ to $\mathrm{H}-\mathrm{H}$ reductive coupling to yield a complex with dihydrogen very weakly bound to the exo face. A subsequent dissociation of $\mathrm{H}_{2}$ to give ( $\left.{ }^{\mathrm{tBu}} \mathrm{PH} \mathrm{HP}\right) \mathrm{IrH}$ is essentially barrierless and slightly exothermic. An alternative pathway for hydrogen loss from ( ${ }^{\mathrm{tBu}} \mathrm{P}^{\mathrm{H}} \mathrm{PP}$ ) $\mathrm{IrH}_{3}$, a concerted heterolytic elimination of $\mathrm{H}_{2}$ across the P-Ir bond of ( $\left.{ }^{\mathrm{tBu}} \mathrm{P} \mathrm{HPP}\right) \mathrm{IrH} \mathrm{H}_{3}$ was also considered. The TS was calculated to have a high free energy, $34.8 \mathrm{kcal} / \mathrm{mol}$, leading to a dihydrogen complex, ('BuPPP) Ir $\left(\mathrm{H}_{2}\right)(\mathrm{H})_{2}$ which could then lose $\mathrm{H}_{2}$, rather than leading directly to loss of $\mathrm{H}_{2}$ (Figure 4). 


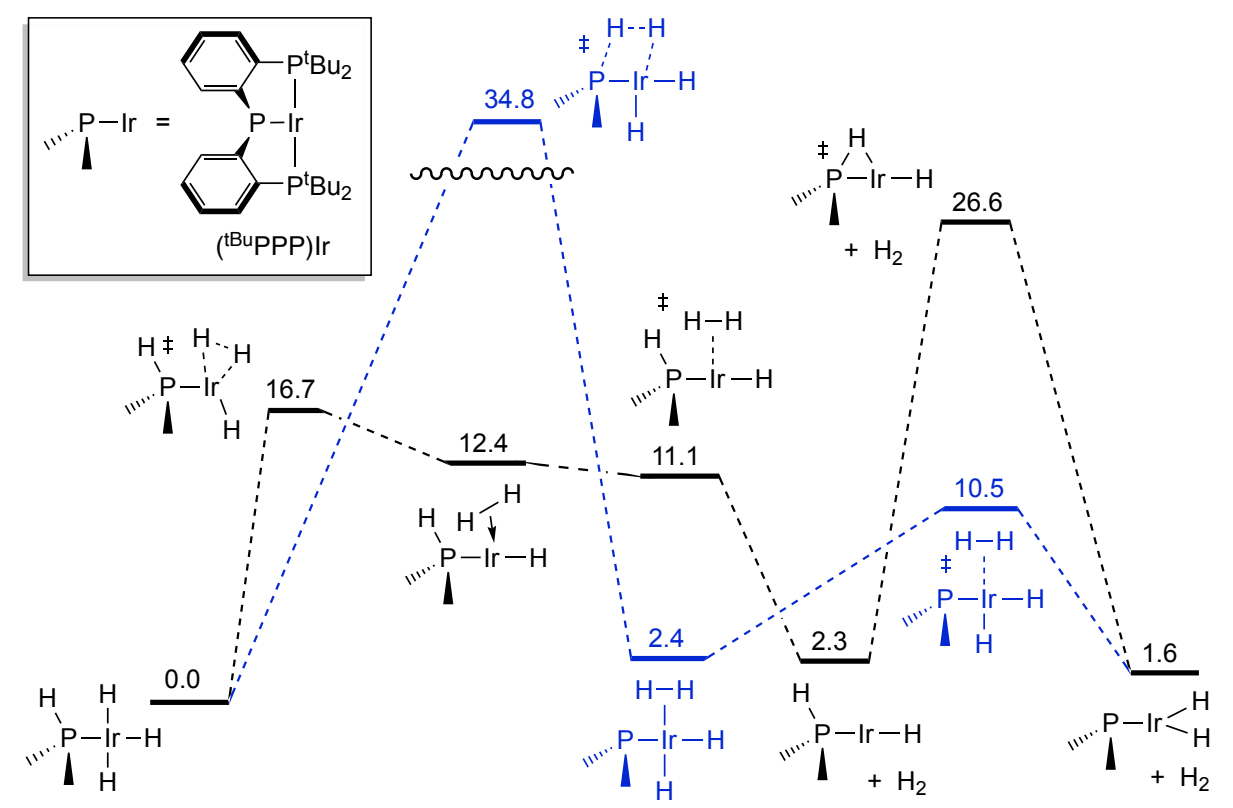

Figure 4. Free energy profile $\left(\Delta \mathrm{G}^{\circ} /(\mathrm{kcal} / \mathrm{mol})\right)$ for loss of $\mathrm{H}_{2}$ from $\left({ }^{\mathrm{tBu}} \mathrm{P}^{\mathrm{H} P P}\right) \operatorname{IrH} \mathrm{H}_{3}$. Reductive elimination of $\mathrm{H}_{2}$ from Ir followed by proton migration (black pathway) is strongly favored over direct heterolytic elimination across P-Ir bond (blue pathway). " $¥$ " indicates a transition state.

Thermodynamically, the overall loss of $\mathrm{H}_{2}$ from ( $\left.{ }^{\mathrm{tBu}} \mathrm{P}^{\mathrm{H}} \mathrm{PP}\right) \mathrm{IrH}_{3}$ is calculated to be slightly endergonic to give either ( $\left.{ }^{\mathrm{tBu} P \mathrm{H} P P}\right) \mathrm{IrH}\left(\Delta \mathrm{G}^{\circ}=2.3 \mathrm{kcal} / \mathrm{mol}\right)$ or ( $\left.{ }^{\mathrm{tBu} P P P}\right) / \mathrm{rH}_{2}\left(\Delta \mathrm{G}^{\circ}=1.6 \mathrm{kcal} / \mathrm{mol}\right)$.

( ${ }^{\text {tBupH} P P)}$ IrH is calculated to undergo transfer of $\mathrm{H}$ (formally $\mathrm{H}^{+}$) from the central phosphorus to iridium to give ('BuPPP) $\mid \mathrm{rH}_{2}$, with a barrier of $\Delta \mathrm{G}^{\ddagger}=24.3 \mathrm{kcal} / \mathrm{mol}$. This reaction is approximately thermoneutral with $\Delta \mathrm{G}^{\circ}=-0.7 \mathrm{kcal} / \mathrm{mol}$. The calculated thermodynamics and reaction barrier are consistent with the experimentally observed equilibrium between ( $\left.{ }^{\mathrm{tBu}} \mathrm{PH}^{\mathrm{H} P}\right) \mathrm{IrH}$ and ( $\left.{ }^{\mathrm{tBu} P P P}\right) \mid \mathrm{rH}_{2}(\Delta \mathrm{G}=-0.4 \mathrm{kcal} / \mathrm{mol})$ and the observed barrier of $\Delta \mathrm{G}^{\ddagger}=25.4$ $\mathrm{kcal} / \mathrm{mol}$ at $60^{\circ} \mathrm{C}$ (Scheme S17). ${ }^{66}$

While the transfer of $\mathrm{H}$ from $\mathrm{P}$ to Ir requires an approximate planarization at the central phosphorus for geometric reasons, it should be noted that the barrier to inversion at $\mathrm{P}$ in ('BuPPP) $\mid \mathrm{rH}_{2}$ is calculated to be quite small; the TS has a free energy only $4.6 \mathrm{kcal} / \mathrm{mol}$ above ( $\left.{ }^{\mathrm{tBu}} \mathrm{PPP}\right) \mid \mathrm{rH}_{2}$. Thus the need for planarity at $\mathrm{P}$ is not the major factor contributing to the substantial kinetic barrier for migration of $\mathrm{H}$ from $\mathrm{P}$ to Ir for ( $\left.{ }^{\mathrm{tBu} P P P}\right) \mathrm{IrH} \mathrm{H}_{2}\left(\Delta \mathrm{G}^{\ddagger}=24.3 \mathrm{kcal} / \mathrm{mol}\right)$. Relatedly, the barrier to proton migration for the conversion of ( $\left.{ }^{\mathrm{tBu}} \mathrm{P}^{\mathrm{H} P P}\right) \mathrm{IrCl}$ to give ( $\left.{ }^{\mathrm{BBu}} \mathrm{PPP}\right) \mathrm{IrHCl}$ (with $\mathrm{Cl}$ in the endo position; Scheme 2 ) is calculated to be very similar, $\Delta \mathrm{G}^{\ddagger}=24.9 \mathrm{kcal} / \mathrm{mol}$ (Figure 5); this value is consistent with the experimental observation that the reaction requires ca. 12 hours to reach completion at room temperature. The proton migration is calculated to lead initially to the exo-hydride isomer, as suggested in Scheme 2, which then undergoes inversion at $P_{C}$ with a relatively small barrier, $\Delta G^{\ddagger}=13.4 \mathrm{kcal} / \mathrm{mol}$ (Figure 5). 


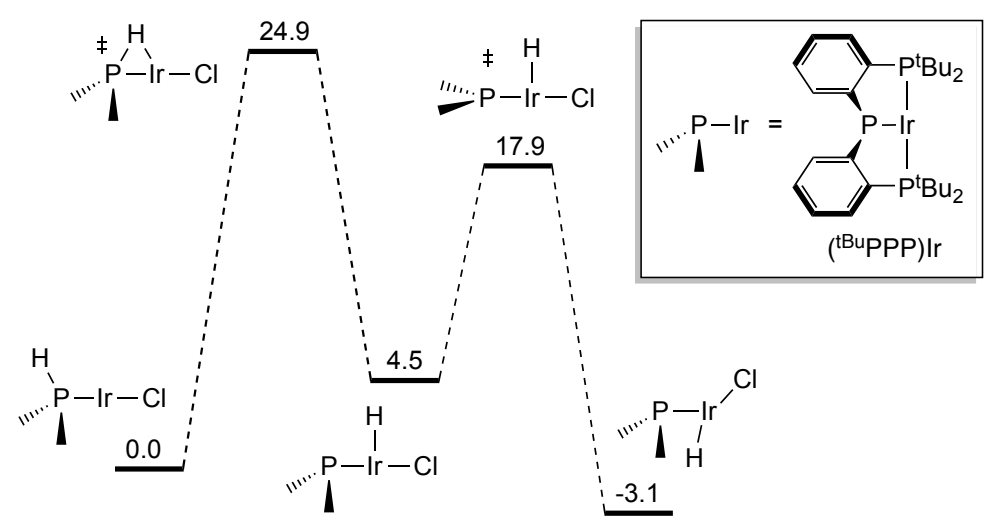

Figure 5. Free energy profile $\left(\Delta \mathrm{G}^{\circ} /(\mathrm{kcal} / \mathrm{mol})\right)$ for conversion of ( $\left.{ }^{\mathrm{tBu} P \mathrm{H} P P}\right) \mid \mathrm{rCl}$ to ( $\left.{ }^{\mathrm{tBu} P P P}\right) \mid \mathrm{rHCl}$ (Cl-exo) via proton migration and inversion at $\mathrm{P}_{\mathrm{c}}$. " $¥$ " indicates a transition state.

Alkane Dehydrogenation by ('BuPPP)Ir: Experimental Studies. The potential ability of ( ${ }^{\text {tBuPPP}}$ )Ir to catalyze alkane transfer-dehydrogenation, in analogy with ( $\left.{ }^{\mathrm{R} P C P}\right)$ Ir complexes, was initially explored with $n$-octane and with 1-hexene as acceptor (eq 1). Conceptually at least, the use of 1-alkene as an acceptor simplifies analysis of the cycle as the hydrogenation segment of the catalytic cycle is essentially the microscopic reverse of dehydrogenation of the terminal position of the $n$-alkane.

$$
\text { n-octane }+ \text { 1-hexene } \rightarrow \text { octenes }+ \text { hexane }
$$

An $n$-octane solution of 1-hexene $(0.2 \mathrm{M})$ and ( $\left.{ }^{\mathrm{tBupH}}{ }^{\mathrm{H} P}\right) \mathrm{IrH} \mathrm{H}_{3}(2.5 \mathrm{mM})$ was heated to $100^{\circ} \mathrm{C}$. Within 2 minutes the color was observed to change from golden yellow to a red color similar to that of a solution of ( $\left.{ }^{\mathrm{tBu}} \mathrm{PPP}\right) \mathrm{IrH} \mathrm{rH}_{2}$ and $\left({ }^{\mathrm{tBu}} \mathrm{P}^{\mathrm{H}} \mathrm{PP}\right) \mathrm{IrH}$. The reaction was monitored by gas chromatography for catalytic transfer dehydrogenation; after 2 minutes of heating $2.2 \mathrm{mM} n$ hexane (ca. 1 equiv), but no octenes, were observed. The solution was then subject to further heating at $100{ }^{\circ} \mathrm{C}$. Very early ( $<1 \mathrm{~min}$ ) within the second period of heating, the solution color changed to a green similar to that of (tBuPPP)Ir(ethylene). After 2 min of heating subsequent to the first $2 \mathrm{~min}, 37 \mathrm{mM}$ octenes (15 TO) and an equal amount of $n$-hexane had been produced (Figure 6); this represents a rate of catalytic alkane dehydrogenation at such temperature that is remarkably high as compared with any previous reports to our knowledge. $33-39,55,64,79-83$ Within $4 \mathrm{~min}$ ( 6 min including the first $2 \mathrm{~min}$ without octene formation) $63 \mathrm{mM}$ octenes (25 TO) had formed. The quantity of hexanes formed was within experimental error equal to the quantities of octenes observed at all times, in accord with eq 1, while the disappearance of 1-hexene was much greater due to isomerization to trans- and cis-2-hexene. 
( ${ }^{\text {BuppPP) }}$ Ir (2.5 mM), n-octane/1-hexene, $100{ }^{\circ} \mathrm{C}$

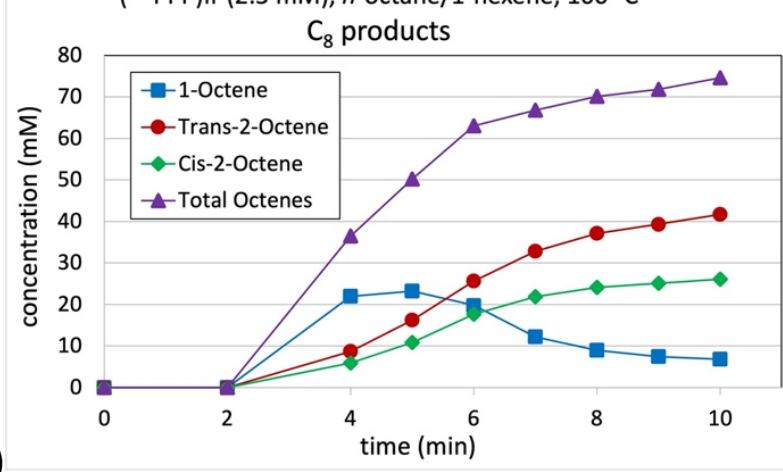

(tBuppP) Ir (2.5 mM), $n$-octane/1-hexene, $100{ }^{\circ} \mathrm{C}$ $\mathrm{C}_{6}$ products

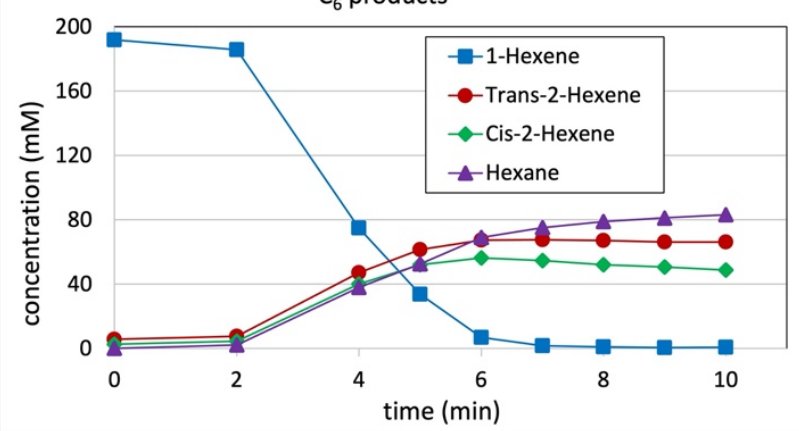

(b)

Figure 6. $n$-Octane/1-hexene $(200 \mathrm{mM})$ transfer dehydrogenation catalyzed by ('BupPP) Ir ( 2.5 $\mathrm{mM}), 100{ }^{\circ} \mathrm{C}$. (a) $\mathrm{C}_{8}$ products. (b) 1-hexene and $\mathrm{C}_{6}$ products.

For comparison, an analogous experiment was conducted with (iPrPCP)Ir as the catalyst, which has previously given the fastest rates of alkane/1-alkene transfer-dehydrogenation reported to date. ${ }^{33-39,55,64,79-83}$ The reaction rate was much slower, approximately by a factor of 300, than was found for ('BuPPP) Ir (Figure 7). Thus ('BuPPP)Ir is apparently by far the fastest catalyst reported to date for $n$-alkane-to-alkene transfer dehydrogenation.

(a)

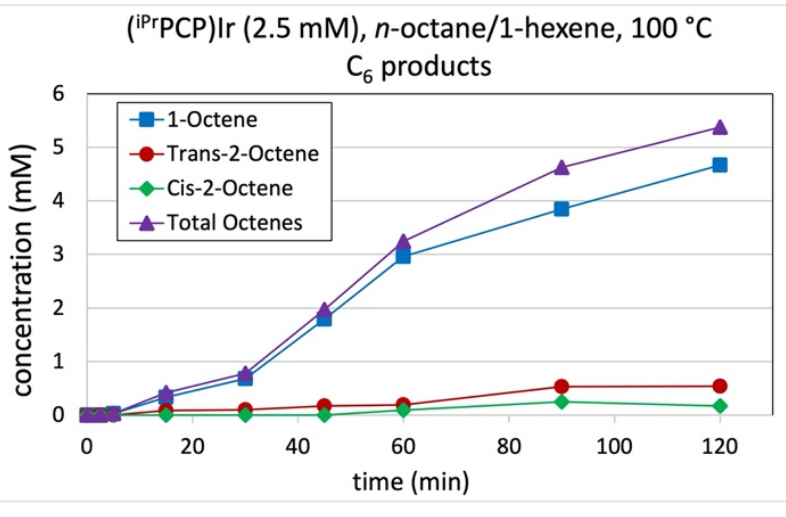

(b)

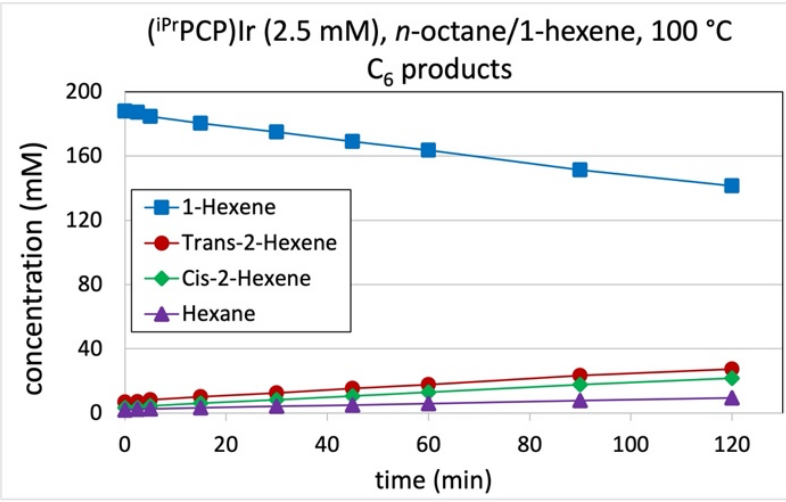

Figure 7. $n$-Octane/1-hexene $(200 \mathrm{mM})$ transfer dehydrogenation catalyzed by (iPrPCP) Ir ( 2.5 $\mathrm{mM}), 100{ }^{\circ} \mathrm{C}$. (a) $\mathrm{C}_{8}$ products. (b) 1-hexene and $\mathrm{C}_{6}$ products.

At early reaction time it can be seen (Figure 6) that the major kinetic product of $n$-octane dehydrogenation by ('BuPPP)Ir is 1-octene. Thus ('BuPPP)Ir shows the very desirable regioselectivity for dehydrogenation of the terminal position of $n$-alkane, as has been found with some, although not all, PCP-type iridium-based catalysts ${ }^{84}$. As the reaction proceeds, the ratio of regioisomers shifts in favor of the thermodynamically more favorable 2-olefins. This is presumably due to some combination of double-bond isomerization and hydrogenation that is selective for 1-octene versus internal octenes. Related to this, the rate of transfer dehydrogenation significantly decreases when the 1-hexene is consumed, although the majority of it has been isomerized to 2-hexenes and not hydrogenated; the 2-hexenes are much 
less effective as hydrogen acceptors. Note that, based on microscopic reversibility, selectivity for hydrogenation of 1-hexene is necessarily correlated with regioselectivity of $n$-alkane dehydrogenation at the terminal position.

While condensed phase olefins are typically preferred as hydrogen acceptors for the sake of convenience, propene offers the advantage over 1-hexene or other 1-alkenes that it cannot undergo isomerization to internal olefins which are seen to be less effective as acceptors. Moreover, with respect to practical considerations at large scale, propene would be much more economical than alpha-olefins. Propene and the propane byproduct also offer the advantage of easy separation from solution, and the possibility of recycling the propane to propene using heterogeneous catalysts ${ }^{85}$ (which are far less effective for the dehydrogenation of higher alkanes in terms of both chemo- and regioselectivity). Accordingly we investigated the use of

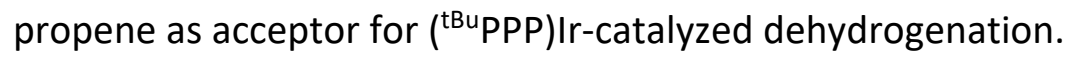

$1 \mathrm{~atm}$ propene was added at room temperature $(9 \mathrm{~mL}$ headspace, $0.37 \mathrm{mmol})$ to an $n$-octane solution of (PHPP) $\mathrm{rH}_{3}(2.5 \mathrm{mM}, 1.0 \mathrm{~mL}, 0.0025 \mathrm{mmol})$. Rapid transfer dehydrogenation resulted at $80^{\circ} \mathrm{C}$, a temperature much lower than that usually employed for alkane dehydrogenation. After 30 min heating, 74 mM (30 TO) total octenes had formed (Figure 8 ), with ca. $12 \%$ of the propene hydrogenated. After 80 min heating, 148 mM (59 TO) total octenes was observed.

(a)
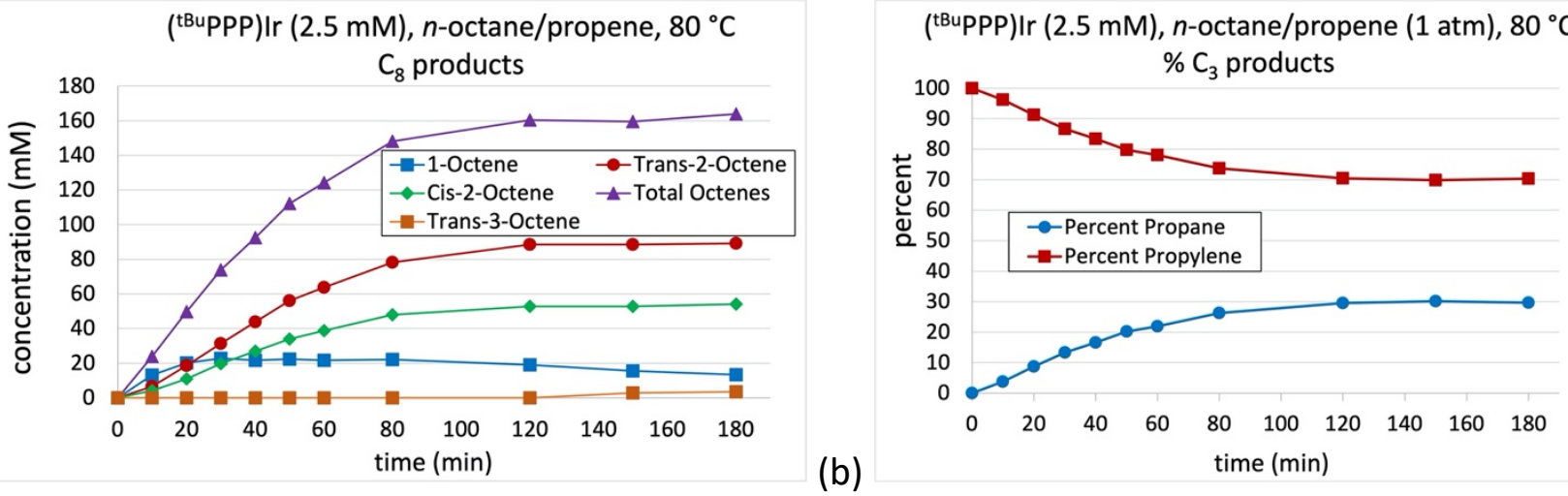

Figure 8. Octane/Propylene ( $1 \mathrm{~atm}, 9 \mathrm{~mL}$ headspace) transfer dehydrogenation catalyzed by ('BupPP) Ir (2.5 mM), $80^{\circ} \mathrm{C}$ (a) Octene Products (b) Percent Composition of Propane/Propylene

For comparison again, a run under the same conditions was conducted with (iPrPCP)Ir as catalyst for $n$-alkane/propene dehydrogenation. 0.24 TO octenes were observed after 5 hours. Thus catalysis by ( ${ }^{\text {tBuPPP }}$ ) Ir is over 1000 times faster than that by ( ${ }^{\text {PrrPCP) }}$ Ir under these conditions. Previously (iPrPCP)Ir had been reported to catalyze $n$-alkane/propene dehydrogenation at $68 \mathrm{TO} / \mathrm{min}$ and $9.6 \mathrm{TO} / \mathrm{min}$ at $180^{\circ} \mathrm{C}$ and $160{ }^{\circ} \mathrm{C}$ respectively under 2 atm propene. A crude Eyring-plot extrapolation from these two points gives an expected rate at 80 ${ }^{\circ} \mathrm{C}$ of $4.2 \times 10^{-4} \mathrm{~min}^{-1}$ under those conditions; thus the rate observed in the present experiment (ca. $8 \times 10^{-4} \mathrm{~min}^{-1}$ ) is not unexpectedly low. 
The turnover rate (at initial time) for $n$-alkane/propene dehydrogenation by ( ${ }^{\text {tBuPPP}}$ )Ir varies inversely with propene pressure (1 atm - 4 atm; Figure S1). These kinetics indicate a resting state of the composition ( $\left.{ }^{\mathrm{tBu}} \mathrm{PPP}\right) \operatorname{Ir}($ propene) and a turnover-limiting step in which propene has reversibly dissociated from the catalyst. This is consistent with the rapid reversible dissociation of propene from ('BuPPP)Ir(propene) noted above.

Alkane Dehydrogenation by ( ${ }^{\text {tBu}}$ PPP)Ir: DFT Computational Studies. DFT calculations on

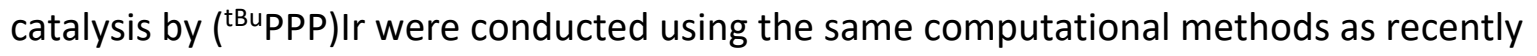
described ${ }^{84}$ in a study of alkane dehydrogenation by ( $\left.{ }^{\mathrm{tBu}} \mathrm{PCP}\right)$ Ir and related complexes. Results of the calculations, illustrated in Figures 9 and 10, reveal that the energy profiles for the reaction

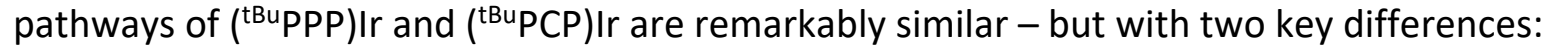

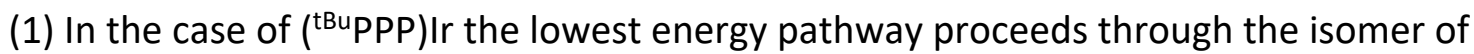
( $\left.{ }^{\text {tBuPPP}}\right) \operatorname{Ir}($ alkene $)(\mathrm{H})_{2}$ in which the olefin is coordinated cis to the central coordinating atom $\left(\mathrm{P}_{\mathrm{c}}\right)$ of the pincer ligand, and thus the hydrides are mutually cis. In contrast, in the case of the ( $\left.{ }^{\mathrm{tBu}} \mathrm{PCP}\right)$ Ir the analogous intermediate has mutually trans hydrides, and the olefin is trans to the PCP ipso-carbon.

(2) The out-of-cycle resting state for both tBuPPP and ${ }^{\text {Bu}}$ PCP complexes is the fourcoordinate $\operatorname{Ir}(\mathrm{I})$ complex with 1-alkene positioned trans to the central coordinating atom. The binding of the olefin is calculated to be significantly weaker in ('BuPPP)Ir(1-alkene) than in ('BuPCP)Ir(1-alkene). The rate-determining $\beta$-H-transfer (BHT) TSs are similar in energy for ${ }^{\text {tBuPPP }}$ and ${ }^{\mathrm{B} u} \mathrm{PCP}$, relative to the respective three-coordinate (pincer) $I \mathrm{r}$ fragments $(23.7 \mathrm{kcal} / \mathrm{mol}$ and $26.0 \mathrm{kcal} / \mathrm{mol}$ ); the overall barrier to catalytic turnover, however, is determined by the free energy difference between the rate-determining $\beta$ - $\mathrm{H}$-transfer TS and the respective fourcoordinate iridium-olefin resting state. At $298 \mathrm{~K}$ the calculated overall free energies of activation $\left(\Delta G^{\ddagger}\right)$ are therefore $28.4 \mathrm{kcal} / \mathrm{mol}$ and $35.6 \mathrm{kcal} / \mathrm{mol}$ for ( $\left.{ }^{\text {tBuPPP}}\right) \mathrm{Ir}$ and ( $\left.{ }^{\mathrm{tBu}} \mathrm{PCP}\right) \mathrm{Ir}$, respectively (Figures 9 and 10). The weaker binding of olefin in the case ( ${ }^{\text {BupPP }}$ )Ir(alkene) can thus be seen as the key factor leading to the much higher activity of ('BuPPP)Ir compared with ('BuPCP)Ir. 


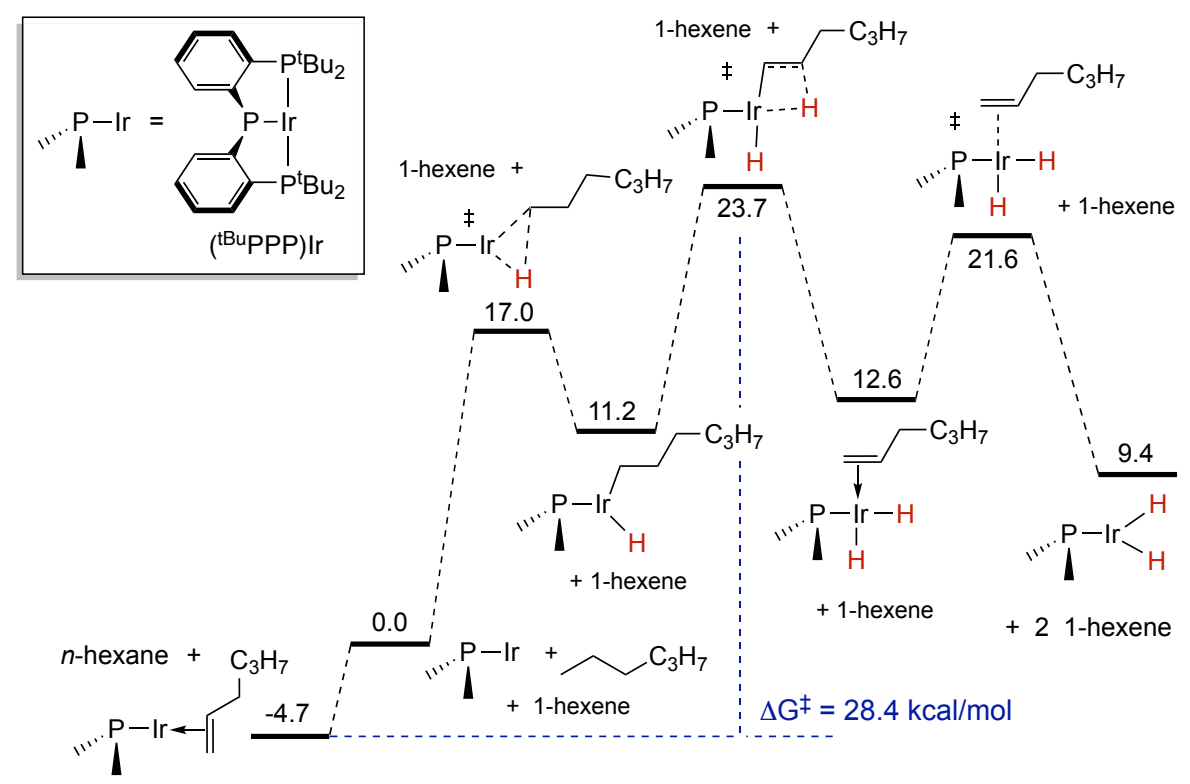

Figure 9. Free energy diagram (kcal/mol) for 1,2-dehydrogenation of $n$-hexane by ( ${ }^{\text {tBuPPP}}$ )Ir to give 1-hexene. Free energies calculated for [ $n$-hexane] $=7.65 \mathrm{M}$ (concentration of neat solvent), [1-hexene] = $1 \mathrm{M}$. " $\neq$ " indicates a transition state.

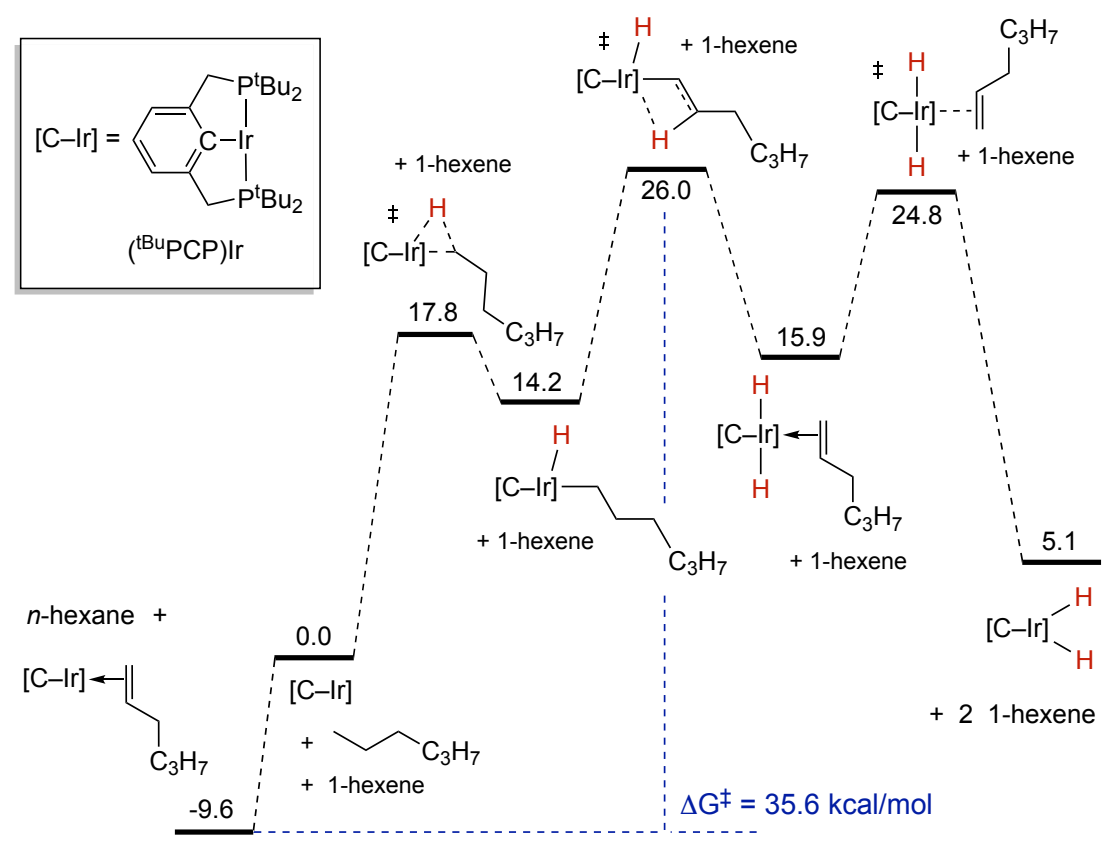

Figure 10. Free energy diagram (kcal/mol) for 1,2-dehydrogenation of $n$-hexane by ( ${ }^{\text {tBuPCP}}$ )Ir to give 1-hexene. Free energies calculated for [ $n$-hexane] $=7.65 \mathrm{M}$ (concentration of neat solvent),

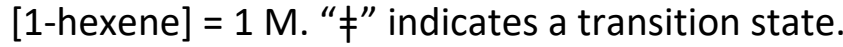




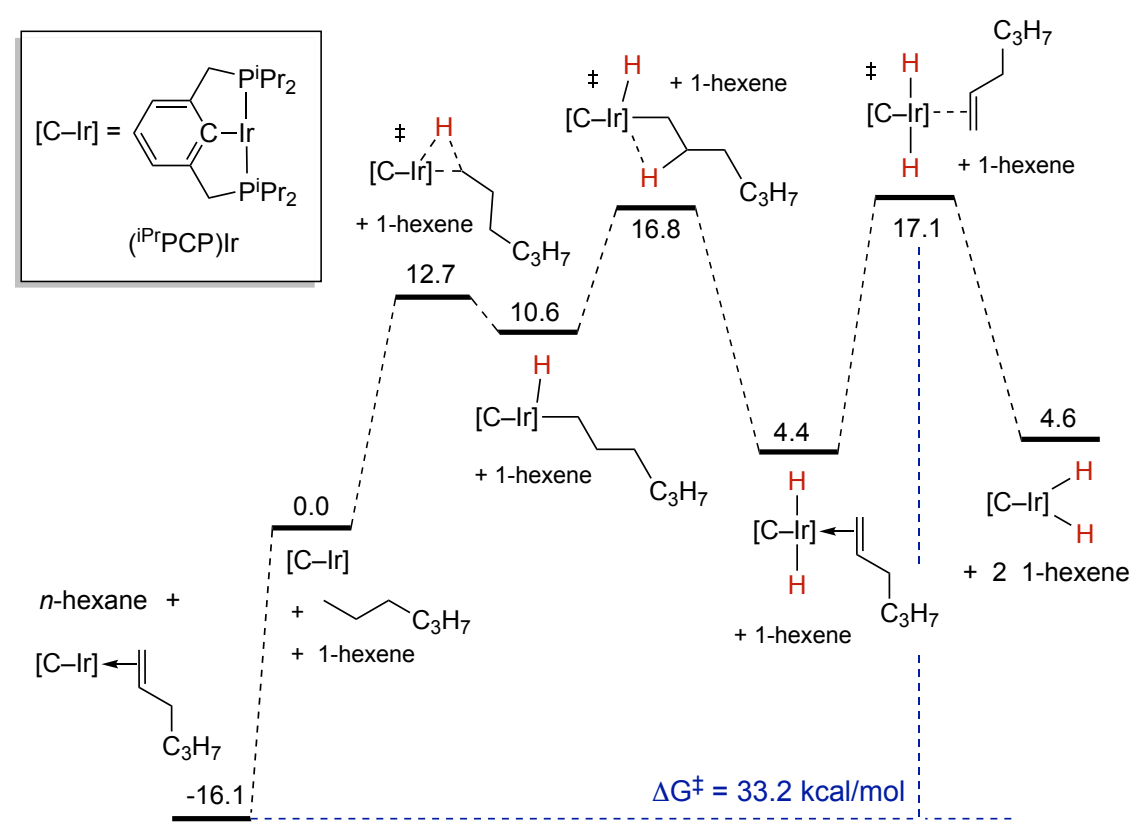

Figure 11. Free energy diagram ( $\mathrm{kcal} / \mathrm{mol}$ ) for 1,2-dehydrogenation of $n$-hexane by ( $\left.{ }^{\mathrm{tBu}} \mathrm{PCP}\right)$ Ir to give 1-hexene. Free energies calculated for $[n$-hexane] $=7.65 \mathrm{M}$ (concentration of neat solvent), [1-hexene] = $1 \mathrm{M}$. “玤 indicates a transition state.

In the case of ( ${ }^{\text {PrPCP) }}$ Ir, which is sterically much less hindered than ( $\left.{ }^{\text {BBupCP }}\right) \mid r$, the TSs for $\beta$ $\mathrm{H}$-transfer and for olefin loss are calculated to be of comparable free energy, equal within the accuracy limits of the calculations (Figure 11). Relative to the respective three-coordinate fragment, both are much lower than the rate-determining TS for either (BВPCP)Ir or ('BuPPP)Ir. Undoubtedly this results from (iPrPCP)Ir being less sterically demanding than ( ${ }^{\mathrm{B} u} \mathrm{PCP}$ ) Ir. The decreased steric crowding of (iPrPCP)Ir, however, also results in much stronger bonding of this fragment to 1-hexene in the resting state. The stronger binding of the olefin to (iPrPCP)Ir cancels out most of the reduction in free energy of the highest barrier relative to the three-coordinate fragment - although not all of the difference; hence (iPrPCP)Ir is a somewhat more active catalyst than ('BuPCP)Ir with an overall calculated barrier of $\Delta \mathrm{G}^{\ddagger}=33.2 \mathrm{kcal} / \mathrm{mol}$ under the assumed conditions. This overall barrier, however, is $4.8 \mathrm{kcal} / \mathrm{mol}$ greater than that for ('BuPPP)।r; at $80^{\circ} \mathrm{C}$ this difference corresponds to a 900 -fold difference in rate which is notably consistent with the experimentally determined difference.

The experimentally determined instability of ('BuPPP) Ir(ethylene) and the dissociation of ethylene on the NMR time scale (with $\Delta \mathrm{H}^{*}=19.8 \mathrm{kcal} / \mathrm{mol}$ ) is consistent with the calculated weaker binding of olefin to ('BuPPP)Ir versus ( ${ }^{\text {tBuPCP }}$ ) Ir. The experimentally determined activation enthalpy is in good agreement with the calculated enthalpy of ethylene binding in ('BuPPP) $) \mathrm{r}\left(\mathrm{C}_{2} \mathrm{H}_{4}\right), \Delta \mathrm{H}^{\circ}=-21.9 \mathrm{kcal} / \mathrm{mol}$ compared with $\Delta \mathrm{H}^{\circ}=-30.6 \mathrm{kcal} / \mathrm{mol}$ for ( $\left.{ }^{\mathrm{BBu}} \mathrm{PCP}\right) \operatorname{Ir}\left(\mathrm{C}_{2} \mathrm{H}_{4}\right)$ (Table S16). Since it is this weak binding which appears be critical in explaining the very high activity of (tBupPP)Ir we investigated this in further detail (Table 1). 
Table 1. Calculated Free Energies of Olefin Binding to (Pincer)Ir

$\left({ }^{R} P E P\right) I r+$ alkene $\rightarrow\left({ }^{R} P E P\right) I r(a l k e n e)(E=P, C) \Delta G^{\circ}(\mathrm{kcal} / \mathrm{mol})$

\begin{tabular}{|l|c|c|c|c|c|c|}
\hline alkene & \multicolumn{2}{|c|}{ ('BuPEP)Ir(alkene) } & \multicolumn{2}{|c|}{ (MePEP) Ir(alkene) } & & \\
\hline & tBuPPP & tBuPCP & MePPP & MePCP & $\Delta$ ('BuPCP - tBuPPP) & $\Delta$ (MePCP - MePPP) \\
\hline ethylene & -7.6 & -16.0 & -22.0 & -22.4 & 8.4 & -0.4 \\
\hline propene & -3.8 & -8.9 & -21.2 & -20.9 & 5.1 & 0.3 \\
\hline 1-hexene & -4.7 & -9.6 & -22.7 & -22.3 & 4.9 & 0.4 \\
\hline trans-2-hexene & 5.4 & -4.7 & -20.9 & -22.1 & 10.1 & -1.2 \\
\hline cis-2-hexene & 5.9 & -3.2 & -19.1 & -21.8 & 9.1 & -2.7 \\
\hline
\end{tabular}

Olefin binding to ( ${ }^{\text {BBuPPP) }}$ ) Ir is calculated to be significantly weaker than to ('BuPCP)Ir for all olefins investigated (Table 1). To determine if the origin of this effect is electronic or steric, we calculated bond strengths for the analogous (MePEP) Ir ( $E=P$ or C) complexes, for which steric effects are presumably much less significant than the ('BuPEP)Ir analogs. In strong contrast with the ('BuPEP)Ir complexes, the Ir-olefin BDFEs for (MePPP)Ir and (MePCP)Ir are strikingly similar. The large differences in the Ir-olefin bond strengths found in the case of ( ${ }^{\text {Bu }}$ PEP) Ir complexes are thus primarily attributable to steric effects. This is consistent with reports indicating that terminal phosphido groups have a trans-influence very similar to that of an aryl group. ${ }^{86}$

If the significantly weaker binding of olefins to ${ }^{\text {tBu}}$ PPP versus ${ }^{\text {tBu}} P C P$ results from greater steric crowding in the former, this raises the question: Why does the increased crowding not raise the energy of the rate-determining TS even more than (or at least as much as) it raises the energy of the four-coordinate (pincer)Ir(olefin) complex? To address this question, the steric profiles of ${ }^{\text {tBuPCP }}$ and ${ }^{\text {tBupPP }}$ were probed using the SambVca 2.1 web application (Figure S54). ${ }^{87}$ The mapped catalytic pocket indicates that ${ }^{\text {tBu} P P P}$ is slightly less sterically hindered than ${ }^{\text {tBu } P C P}$ (79.1\% buried versus $85.7 \%$ buried) (Table 2). But more important than the overall buried volume is the arrangement of the steric bulk, which is radically different for the two complexes.

Table 2. Percent buried free volumes of hemispheres centered on three open coordination sites of ('BupPP)Ir and ('BuPCP)Ir

\begin{tabular}{|l|c|c|c|c|}
\hline & \%BurVol total & cis-exo face & cis-endo face & trans face \\
\hline ('BuPPP)Ir & $79.1 \%$ & $66.2 \%$ & $92.0 \%$ & $84.9 \%$ \\
\hline ('BuPCP)Ir & $85.7 \%$ & $85.9 \%$ & $85.6 \%$ & $78.8 \%$ \\
\hline
\end{tabular}



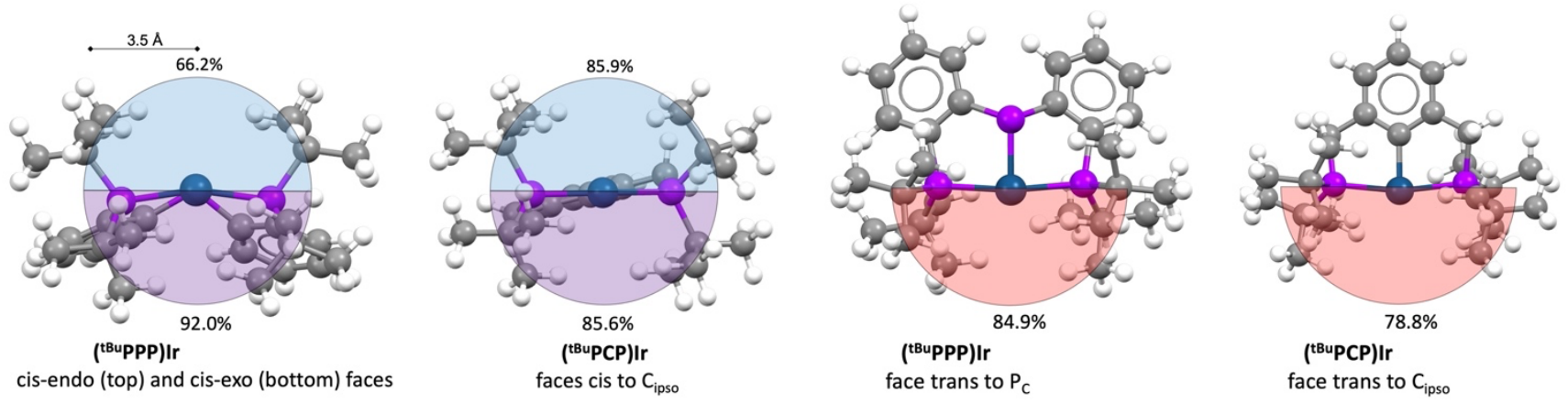

Figure 12. Illustration of buried volumes of hemispheres centered on three open coordination sites of (tBupPP) Ir and ( $\left.{ }^{\mathrm{tBu}} \mathrm{PCP}\right) \mathrm{Ir}$

For a six-coordinate ( ${ }^{\text {tBuPEP}}$ ) Ir (E = C or P) complex, three coordination sites are available. The percent buried volume of the hemisphere approximately centered on each of those three sites was determined. As indicated in Table 2 and Figure 12, in the case of ( ${ }^{\mathrm{B} u}$ PPP) Ir, the hemisphere centered on the (exo) site cis to the central coordinating atom $\left(P_{C}\right)$ is quite uncrowded ( $\mathrm{BV}=66 \%)$. The face trans to $\mathrm{P}_{\mathrm{C}}$ is crowded $(\mathrm{BV}=85 \%)$ and the endo cis face is even more crowded (BV = 92\%). In marked contrast, for ( $\left.{ }^{\mathrm{tBu} P C P}\right)$ Ir, the faces cis to $C_{i p s o}$ are both significantly more crowded ( $B V=86 \%$ ) than the face trans to $C_{i p s o}(B V=79 \%)$.

Viewing the BHT TS as having a geometry approximately resembling the olefin dihydride product to which it leads, the arrangement of steric bulk in ('BuPCP)Ir would favor the BHT TS that leads to the olefin dihydride isomer with the olefin trans to $C_{i p s o}$. It also favors, however, the resting state in which the olefin is trans to $C_{i p s o}$, which contributes to an increase in the overall reaction barrier.

In sharp contrast, in the case of ( ${ }^{\text {Bu }}$ PPP) Ir, the arrangement of steric bulk favors the BHT TS leading to the olefin dihydride isomer with the olefin at the very uncrowded exo cis site. But while the crowding at the site trans to $P_{c}$ allows the presence of a hydride (or incipient hydride) without much energetic penalty, it significantly raise the energy of the four-coordinate $d^{8}$ resting state in which the olefin resides at that site.

The critical factor favoring catalytic activity of ( ${ }^{\text {Bu }}$ PPP) Ir versus ( ${ }^{\text {tBuPCP }}$ )Ir is thus the destabilization of the four-coordinate (pincer)Ir(olefin) resting state relative to the BHT TS, due to the positioning of steric bulk specifically at the coordination site trans to the central coordinating atom. The steric demands at that site are largely circumvented by a BHT TS that leads to the cis-dihydride olefin ${ }^{\text {tBupPP }}$ complex, in contrast with ( ${ }^{\mathrm{B} u} \mathrm{PCP}$ ) Ir for which the most favorable BHT TS leads to the trans-dihydride. It is noteworthy in this context that what appear to be the most active catalysts for $n$-alkane dehydrogenation previously known, triptycenebased PCP-pincer iridium complexes reported by Bézier and Brookhart, are unusual in that they also have a central coordinating group that is non-planar (tetrahedral carbon). ${ }^{33,}$,9, 81-83 
The different isomeric pathways can have additional implications, beyond relative destabilization of the resting state, for both activity and regioselectivity. $\beta$ - $\mathrm{H}$-transfer is ratedetermining for both ( $\left.{ }^{\mathrm{BB}} \mathrm{PPP}\right)$ )Ir and ('BuPCP)Ir pathways, and the TSs for the two fragments have very similar free energies relative to the respective three-coordinate fragment. The subsequent step in the cycles, however, loss of olefin, has a TS that is $3.2 \mathrm{kcal} / \mathrm{mol}$ higher for ('BuPCP) Ir(1hexene) than for ('BuPPP)Ir(1-hexene), although the product of olefin dissociation is actually 4.3 $\mathrm{kcal} / \mathrm{mol}$ lower for ( $\left.{ }^{\mathrm{tBu}} \mathrm{PCP}\right) \operatorname{Ir}(1-$ hexene). This kinetic barrier to loss of alkene is attributable to the formation, as olefin dissociates, of a very high-energy trans-dihydride, while relaxation to a dihydride with an acute $\mathrm{H}-\mathrm{Ir}-\mathrm{H}$ angles occurs only after the Ir-olefin bond is essentially fully broken. ${ }^{84}$ In contrast the cis-dihydride geometry is only slightly higher than the relaxed geometry ${ }^{88}$; thus the kinetics of olefin dissociation from the cis dihydride (or addition to the cis dihydride) are more facile. While the kinetic barrier to olefin loss has no effect on the overall barrier or selectivity in the case of ( $\left.{ }^{\mathrm{tBu} P C P}\right) \operatorname{Ir}(1-h e x e n e)$, in the case of ( $\left.{ }^{\text {PPr }} \mathrm{PCP}\right) \operatorname{Ir}$ the TS for olefin dissociation is calculated to be very slightly higher than the TS for $\beta$-H-transfer, although the difference is too small to be considered meaningful. We have shown, however, that the barrier to olefin dissociation plays an important role in both the rate and selectivity of catalytic alkane dehydrogenation by the closely related fragment ( $\left.{ }^{\mathrm{B} u} \mathrm{POCOP}\right) \mid \mathrm{r}^{84}$ which has oxygen instead of methylene linkers connecting the phosphino groups to the central arene ring. For dehydrogenation by ( ${ }^{\mathrm{tBu}} \mathrm{POCOP}$ )Ir, as well as other derivatives with one or two oxygen linkers, the kinetic barrier to olefin dissociation is high enough that it becomes the rate-determining step. This therefore contributes to the overall reaction barrier and, moreover, it was found to be responsible for a lack of regioselectivity for dehydrogenation at the $n$-alkane terminal position. ${ }^{84}$

\section{- CONCLUSIONS}

Iridium complexes of a bulky triphosphorus-pincer containing a secondary phosphine have been synthesized and their chemistry explored. 1,2-migration of $\mathrm{H}$ from phosphorus to iridium has been observed, with free energy barriers of ca. $25 \mathrm{kcal} / \mathrm{mol}$. In the case of ( $\left.{ }^{\mathrm{tBu}} \mathrm{P}^{\mathrm{H}} \mathrm{PP}\right) \mathrm{IrH}$ the migration is reversible and approximately thermoneutral. This represents, to our knowledge, the first example of a reversible metal-phosphorus proton transfer.

Both the ${ }^{\mathrm{tBu}} \mathrm{PH} P \mathrm{P}$ pincer and the deprotonated phosphido-based ${ }^{\mathrm{tBu}} \mathrm{PPP}$ pincer have a pyramidal central phosphorus which leads to a very unsymmetrical environment in which one coordination site cis to $\mathrm{P}_{\mathrm{c}}$ is very crowded (the endo face) while the other such site (exo) is very open. As a result, $\mathrm{H}_{2}$ addition to ( $\left.{ }^{\mathrm{tBu}} \mathrm{P}^{\mathrm{H}} \mathrm{PP}\right) \mathrm{IrH}$ to give $\left({ }^{\mathrm{tBu}} \mathrm{P}^{\mathrm{H}} \mathrm{PP}\right) \mathrm{IrH} \mathrm{H}_{3}$, and the reverse $\mathrm{H}_{2}$ elimination, occur with high regioselectivity at the exo face. The pyramidal geometry at $\mathrm{P}_{c}$ also results in particularly pronounced crowding at the site trans to $P_{c}$.

The ( $\left.{ }^{R} P P P\right)$ Ir fragment is formally analogous to ( $\left.{ }^{R} P C P\right)$ Ir species which are well known to catalyze alkane dehydrogenation. ('BuPPP)Ir is found to catalyze $n$-alkane transfer dehydrogenation, using propene as a hydrogen acceptor, over a thousand fold faster than 
$\left({ }^{\text {iPr }} \mathrm{PCP}\right)$ Ir, the previously reported fastest catalyst for such reactions. Alkane dehydrogenation with appreciable rates can thus be achieved at unprecedentedly low temperatures. ${ }^{89}$

The origin of the high catalytic activity has been elucidated through a combination of mechanistic experimental and computational studies. $\beta$-H-transfer (BHT) by the alkyl hydride that is formed by alkane $\mathrm{C}-\mathrm{H}$ addition is calculated to be the rate-limiting step. The energy of the BHT TS, relative to the (pincer)Ir fragment, is found to be comparable for (tBuPPP)Ir and ('BuPCP)Ir catalysts. In the case of ('BuPPP)Ir, however, the lowest BHT TS leads to a cis-dihydride intermediate with an olefin coordinated cis (exo) to the central coordinating atom of the pincer ligand $\left(P_{c}\right)$. In contrast, in the case of ( $\left.{ }^{\mathrm{tBu}} \mathrm{PCP}\right) \mathrm{Ir}$, the lowest BHT TS leads to a trans-dihydride complex with the olefin positioned trans to the ipso-carbon of the phenyl ring.

Although the BHT TSs are of similar energy relative to the respective (pincer)Ir fragments, olefin is bound much more weakly in the resting state, (pincer)Ir(olefin), in the case of ('BuPPP)Ir(olefin) than in ('BuPCP)Ir(olefin). Computational studies reveal that the trans influence of $\mathrm{P}_{\mathrm{c}}$ and $\mathrm{C}_{\mathrm{ipso}}$ are very similar, but crowding is much greater at the site trans to the central coordinating atom in ('BuPPP) Ir(olefin) and this is responsible for the much weaker olefin binding.

Thus, in the case of (tBuPPP) Ir the very open exo coordination site permits a facile alkane dehydrogenation pathway in which olefin is formed at that site, while the much less sterically demanding hydrides occupy the other two, much more crowded, coordination sites. In the case of ('BuPCP)Ir the most open site is trans to $C_{\text {ipso; }}$ this results in a comparably facile pathway in which the olefin is formed at that site. Critically, however, the same lack of crowding at that site also allows strong bonding of olefin in the resting state, ( ${ }^{\text {Bu }}$ PCP) Ir(olefin), thus increasing the overall barrier to catalysis. Thus, the unprecedented activity of alkane dehydrogenation by ('BuPPP)Ir is largely attributable to the high degree of crowding at the coordination site trans to the central coordination atom, $\mathrm{P}_{\mathrm{c}}$, along with a particular lack of crowding at the (exo) coordination site cis to $\mathrm{P}_{\mathrm{C}}$.

Three-coordinate $\mathrm{d}^{8}$ fragments play an important role in the functionalization of $\mathrm{C}-\mathrm{H}$ bonds and other catalytic reactions, and frequently the resting states are four-coordinate planar $\mathrm{d}^{8}$ complexes. The general architectural motif which proves very favorable in the present system may perhaps therefore be applicable toward achieving high levels of catalytic activity based on $d^{8}$ transition metal fragments more broadly. 


\section{- ASSOCIATED CONTENT}

\section{Supporting Information}

The Supporting Information is available free of charge on the ACS Publications website at DOI: $10.1021 /$ jacs.xxxx.

Complete experimental details and synthetic procedures, NMR data, computational details, computed energies and thermodynamic quantities, percent buried volumes (PDF) Optimized structures for calculated species (.mol format) (ZIP)

Crystallographic data for ( ${ }^{\text {BuPPP}}$ ) IrHCl, CCDC 2119899 (CIF)

Crystallographic data for ( $\left.{ }^{\mathrm{Eu}} \mathrm{P}^{\mathrm{H}} \mathrm{PP}\right) \mathrm{IrH} \mathrm{H}_{3}, \mathrm{CCDC} 2087441$ (CIF)

Crystallographic data for ('BupPP) Ir(CO), CCDC 2087439 (CIF)

\section{- AUTHOR INFORMATION}

\section{Corresponding Author}

Alan S. Goldman - Department of Chemistry and Chemical Biology, Rutgers, The State University of New Jersey, New Brunswick, New Jersey 08854, United States; orcid.org/0000-0002-2774-710X; Email: alan.goldman@rutgers.edu

\section{Authors}

Benjamin M. Gordon - Department of Chemistry and Chemical Biology, Rutgers, The State University of New Jersey, New Brunswick, New Jersey 08854, United States; orcid.org/0000-0003-4685-8419

Nicholas Lease - Department of Chemistry and Chemical Biology, Rutgers, The State University of New Jersey, New Brunswick, New Jersey 08854, United States

Faraj Hasanayn - Department of Chemistry, American University of Beirut, Beirut 1107 2020, Lebanon; orcid.org/0000-0003-3308-7854

Thomas J. Emge - Department of Chemistry and Chemical Biology, Rutgers, The State University of New Jersey, New Brunswick, New Jersey 08854, United States

Complete contact information is available at:

https://pubs.acs.org/10.1021/jacs.xxxxx

\section{Notes}

The authors declare no competing financial interests.

ACKNOWLEDGMENTS. This work was supported by the U. S. Department of Energy Office of Science (DE-SC0020139).

\section{- REFERENCES}

(1) Tiddens, M. R.; Moret, M.-E., Metal-Ligand Cooperation at Phosphine-Based Acceptor Pincer Ligands. In Metal-Ligand Co-Operativity: Topics in Organometallic Chemistry, Gerard van Koten, K. K., Marc-Etienne Moret, Ed. Springer, Cham: 2020; Vol. 68.

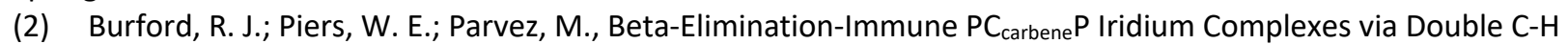
Activation: Ligand-Metal Cooperation in Hydrogen Activation Organometallics 2012, 31, 2949-2952.

(3) Comanescu, C. C.; Vyushkova, M.; Iluc, V. M., Palladium carbene complexes as persistent radicals Chem. Sci. 2015, 6, 4570-4579.

(4) Shih, W.-C.; Ozerov, O. V., Synthesis and Characterization of PBP Pincer Iridium Complexes and Their Application in Alkane Transfer Dehydrogenation Organometallics 2017, 36, 228-233. 
(5) Cao, Y.; Shih, W.-C.; Ozerov, O. V., Addition of O-H, N-H, and F-H Bonds across a Boryl-Iridium Unit Organometallics 2019, 38, 4076-4081.

(6) Cao, Y.; Shih, W.-C.; Bhuvanesh, N.; Ozerov, O. V., Reversible addition of ethylene to a pincer-based boryliridium unit with the formation of a bridging ethylidene Chem. Sci. 2020, 11, 10998-11002.

(7) Cao, Y.; Shih, W.-C.; Bhuvanesh, N.; Zhou, J.; Ozerov, O. V., Cooperative C-H activation of pyridine by PBP complexes of Rh and Ir can lead to bridging 2-pyridyls with different connectivity to the B-M unit Chem. Sci. 2021, Ahead of Print.

(8) Rauch, M.; Kar, S.; Kumar, A.; Avram, L.; Shimon, L. J. W.; Milstein, D., Metal-Ligand Cooperation Facilitates Bond Activation and Catalytic Hydrogenation with Zinc Pincer Complexes J. Am. Chem. Soc. 2020, 142, 1451314521.

(9) Zhou, Q.-Q.; Zou, Y.-Q.; Kar, S.; Diskin-Posner, Y.; Ben-David, Y.; Milstein, D., Manganese-Pincer-Catalyzed Nitrile Hydration, $\alpha$-Deuteration, and $\alpha$-Deuterated Amide Formation via Metal Ligand Cooperation ACS Catal. 2021, 11, 10239-10245.

(10) Camp, A. M.; Kita, M. R.; Blackburn, P. T.; Dodge, H. M.; Chen, C.-H.; Miller, A. J. M., Selecting Double Bond Positions with a Single Cation-Responsive Iridium Olefin Isomerization Catalyst J. Am. Chem. Soc. 2021, 143, 27922800.

(11) Poitras, A. M.; Oliemuller, L. K.; Hatzis, G. P.; Thomas, C. M., Highly Selective Hydroboration of Terminal Alkenes Catalyzed by a Cobalt Pincer Complex Featuring a Central Reactive N-Heterocyclic Phosphido Fragment Organometallics 2021, 40, 1025-1031.

(12) Wang, Q.; Manzano, R. A.; Tinnermann, H.; Sung, S.; Leforestier, B.; Krämer, T.; Young, R. D., Access to and Reactivity of FeO, Fe-I, Fel, and Fell PCcarbeneP Pincer Complexes Angew. Chem., Intl. Ed. 2021, 60, 18168-18177. (13) Kar, S.; Rauch, M.; Kumar, A.; Leitus, G.; Ben-David, Y.; Milstein, D., Selective Room-Temperature Hydrogenation of Amides to Amines and Alcohols Catalyzed by a Ruthenium Pincer Complex and Mechanistic Insight ACS Catal. 2020, 10, 5511-5515.

(14) Gunanathan, C.; Milstein, D., Bond Activation and Catalysis by Ruthenium Pincer Complexes Chem. Rev. 2014, 114, 12024-12087.

(15) Fryzuk, M. D.; Montgomery, C. D.; Rettig, S. J., Synthesis and reactivity of ruthenium amide-phosphine complexes. Facile conversion of a ruthenium amide to a ruthenium amine via dihydrogen activation and orthometalation. X-ray structure of $\mathrm{RuCl}\left(\mathrm{C}_{6} \mathrm{H}_{4} \mathrm{PPh}_{2}\right)\left[\mathrm{NH}\left(\mathrm{SiMe}_{2} \mathrm{CH}_{2} \mathrm{PPh}_{2}\right)_{2}\right]$ Organometallics 1991, 10, 467-473. (16) Fryzuk, M. D.; MacNeil, P. A.; Rettig, S. J., Stereoselective formation of rhodium and iridium hydrides via intramolecular hydrogen bonding J. Am. Chem. Soc. 1987, 109, 2803-2812.

(17) Ikariya, T.; Blacker, A. J., Asymmetric transfer hydrogenation of ketones with bifunctional transition metalbased molecular catalysts Acc. Chem. Res. 2007, 40, 1300-1308.

(18) Zhao, B.; Han, Z.; Ding, K., The N-H functional group in organometallic catalysis Angew. Chem., Intl. Ed. 2013, $52,4744-4788$.

(19) Morris, R. H., Exploiting metal-ligand bifunctional reactions in the design of iron asymmetric hydrogenation catalysts Acc. Chem. Res. 2015, 48, 1494-1502.

(20) Fryzuk, M. D.; Bhangu, K., Activation of dihydrogen by organo-iridium-phosphido complexes. Evidence for .alpha.-hydrogen abstraction by a terminal phosphide ligand J. Am. Chem. Soc. 2002, 110, 961-963.

(21) Derrah, E. J.; Pantazis, D. A.; McDonald, R.; Rosenberg, L., A Highly Reactive Ruthenium Phosphido Complex Exhibiting Ru-P $\pi$-Bonding Organometallics 2007, 26, 1473-1482.

(22) Dahlenburg, L.; Höck, N.; Berke, H., Oligophosphan-Liganden, XXIX. Chelatphosphan-stabilisierte Rhodium(I)Komplexe mit terminalen Phosphido-Liganden: Synthese, Reaktionen und Elektronenstruktur Chem. Ber. 1988, 121, 2083-2093.

(23) Roddick, D. M.; Santarsiero, B. D.; Bercaw, J. E., Synthesis and reactivity of cyclopentadienylhafnium phosphido complexes. Hydrogenolysis and carbon monoxide insertion for Hf-PR 2 bonds J. Am. Chem. Soc. 1985, $107,4670-4678$.

(24) Hoyle, M.-A. M.; Pantazis, D. A.; Burton, H. M.; McDonald, R.; Rosenberg, L., Benzonitrile Adducts of Terminal Diarylphosphido Complexes: Preparative Sources of "Ru=PR2" Organometallics 2011, 30, 6458-6465.

(25) Gediga, M.; Feil, C. M.; Schlindwein, S. H.; Bender, J.; Nieger, M.; Gudat, D., N-Heterocyclic Phosphenium Complex of Manganese: Synthesis and Catalytic Activity in Ammonia Borane Dehydrogenation Chemistry 2017, 23, 11560-11569.

(26) Birchall, N.; Feil, C. M.; Gediga, M.; Nieger, M.; Gudat, D., Reversible cooperative dihydrogen binding and transfer with a bis-phosphenium complex of chromium Chem. Sci. 2020, 11, 9571-9576. 
(27) Dillon, K. B.; Mathey, F.; Nixon, J. F., Phosphorus: The Carbon Copy: From Organophosphorus to Phosphaorganic Chemistry Wiley: 1998; p 366.

(28) Gupta, M.; Hagen, C.; Flesher, R. J.; Kaska, W. C.; Jensen, C. M., A Highly Active Alkane Dehydrogenation Catalyst: Stabilization of Dihydrido Rh and Ir Complexes by a P-C-P Pincer Ligand Chem. Commun. 1996, $2083-2084$. (29) Morales-Morales, D., Iridium-mediated alkane dehydrogenation Iridium Complexes in Organic Synthesis 2009, 325-344.

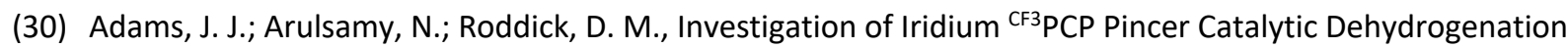
and Decarbonylation Chemistry Organometallics 2012, 31, 1439-1447.

(31) Findlater, M.; Choi, J.; Goldman, A. S.; Brookhart, M., Alkane dehydrogenation. In Catal. Met. Complexes, Springer: 2012; Vol. 38, pp 113-141.

(32) Shi, Y.; Suguri, T.; Dohi, C.; Yamada, H.; Kojima, S.; Yamamoto, Y., Highly Active Catalysts for the Transfer Dehydrogenation of Alkanes: Synthesis and Application of Novel 7-6-7 Ring-based Pincer Iridium Complexes Chem. - Eur. J. 2013, 19, 10672-10689.

(33) Bezier, D.; Brookhart, M., Transfer dehydrogenations of alkanes and related reactions using iridium pincer complexes Top. Organomet. Chem. 2016, 56, 189-207.

(34) Kumar, A.; Bhatti, T. M.; Goldman, A. S., Dehydrogenation of Alkanes and Aliphatic Groups by Pincer-Ligated Metal Complexes Chem. Rev. 2017, 117, 12357-12384.

(35) Polukeev, A. V.; Wendt, O. F., Cyclohexane-Based Phosphinite Iridium Pincer Complexes: Synthesis, Characterization, Carbene Formation, and Catalytic Activity in Dehydrogenation Reactions Organometallics 2017, 36, 639-649.

(36) Fang, H.; Liu, G.; Huang, Z., Pincer iridium and ruthenium complexes for alkane dehydrogenation. In Pincer Compounds Chemistry and Applications, Morales-Morales, D., Ed. Elsevier B.V.: Amsterdam, 2018; pp 383-399.

(37) Fang, H.; Liu, G.; Huang, Z., Dehydrogenation of alkanes using molecular catalysts. In Alkane Functionalization, Pombeiro, A. J. L.; Silva, M. F. C. G. d., Eds. Wiley-Blackwell: Oxford, UK, 2019; pp 467-483. (38) Das, K.; Kumar, A., Alkane dehydrogenation reactions catalyzed by pincer-metal complexes Adv. Organomet. Chem. 2019, 72, 1-57.

(39) Budweg, S.; Junge, K.; Beller, M., Catalytic oxidations by dehydrogenation of alkanes, alcohols and amines with defined (non)-noble metal pincer complexes Catal. Sci. Technol. 2020, 10, 3825-3842.

(40) For related "CCC" pincer-Ir complexes with NHC groups in place of the phosphino groups of PCP ligands see for example: (a) Chianese, A. R.; Mo, A.; Lampland, N. L.; Swartz, R. L.; Bremer, P. T. "Iridium Complexes of CCCPincer N-Heterocyclic Carbene Ligands: Synthesis and Catalytic C-H Functionalization" Organometallics 2010, 29, 3019-3026. (b) Chianese, A. R.; Drance, M. J.; Jensen, K. H.; McCollom, S. P.; Yusufova, N.; Shaner, S. E.; Shopov, D. Y.; Tendler, J. A. "Acceptorless Alkane Dehydrogenation Catalyzed by Iridium CCC-Pincer Complexes" Organometallics 2014, 33, 457-464. (c) Zuo, W.; Braunstein, P. "N-Heterocyclic Dicarbene Iridium(III) Pincer Complexes Featuring Mixed NHC/Abnormal NHC Ligands and Their Applications in the Transfer Dehydrogenation of Cyclooctane" Organometallics 2012, 31, 2606-2615.

(41) Hwang, S. J.; Tanushi, A.; Radosevich, A. T., Enthalpy-Controlled Insertion of a "Nonspectator" Tricoordinate Phosphorus Ligand into Group 10 Transition Metal-Carbon Bonds J. Am. Chem. Soc. 2020, 142, 21285-21291.

(42) Tanushi, A.; Radosevich, A. T., Insertion of a Nontrigonal Phosphorus Ligand into a Transition Metal-Hydride: Direct Access to a Metallohydrophosphorane J. Am. Chem. Soc. 2018, 140, 8114-8118.

(43) Fu, R.; Goddard, W. A.; Cheng, M.-J.; Nielsen, R. J., Computational Design of a Pincer Phosphinito Vanadium ((OPO)V) Propane Monoxygenation Homogeneous Catalyst Based on the Reduction-Coupled Oxo Activation (ROA) Mechanism ACS Catal. 2016, 7, 356-364.

(44) Cheng, M. J.; Fu, R.; Goddard, W. A., Design and validation of non-metal oxo complexes for C-H activation Chem. Commun. 2014, 50, 1748-1750.

(45) Mankad, N. P.; Rivard, E.; Harkins, S. B.; Peters, J. C., Structural Snapshots of a Flexible $\mathrm{Cu}_{2} \mathrm{P}_{2} \mathrm{Core}$ that Accommodates the Oxidation States $\mathrm{Cu}^{\prime} \mathrm{Cu}^{\prime}, \mathrm{Cu}^{1.5} \mathrm{Cu}^{1.5}$, and $\mathrm{Cu}^{\prime \prime} \mathrm{Cu}^{\prime \prime} \mathrm{J}$. Am. Chem. Soc. 2005, 127, 16032-16033.

(46) Mankad, N. P.; Harkins, S. B.; Antholine, W. E.; Peters, J. C., Multifrequency EPR studies of $[\mathrm{Cu}(1.5) \mathrm{Cu}(1.5)](+)$ for $\mathrm{Cu}_{2}\left(\mathrm{mu}-\mathrm{NR}_{2}\right)_{2}$ and $\mathrm{Cu}_{2}\left(\mathrm{mu}-\mathrm{PR}_{2}\right)_{2}$ diamond cores Inorg. Chem. 2009, 48, 7026-7032.

(47) Mazzeo, M.; Strianese, M.; Kuehl, O.; Peters, J. C., Phosphido pincer complexes of platinum: synthesis, structure and reactivity Dalton Trans. 2011, 40, 9026-9033.

(48) Mazzeo, M.; Lamberti, M.; Massa, A.; Scettri, A.; Pellecchia, C.; Peters, J. C., Phosphido pincer complexes of palladium as new efficient catalysts for allylation of aldehydes Organometallics 2008, 27, 5741-5743.

(49) Whited, M. T.; Rivard, E.; Peters, J. C., Complexes of iron and cobalt with new tripodal amido-polyphosphine hybrid ligands Chem. Commun. 2006, 1613-1615. 
(50) Bauer, R. C.; Gloaguen, Y.; Lutz, M.; Reek, J. N.; de Bruin, B.; van der Vlugt, J. I., Pincer ligands with an allphosphorus donor set: subtle differences between rhodium and palladium Dalton Trans. 2011, 40, 8822-8829. (51) Gloaguen, Y.; Jacobs, W.; de Bruin, B.; Lutz, M.; van der Vlugt, J. I., Reactivity of a mononuclear iridium(I) species bearing a terminal phosphido fragment embedded in a triphosphorus ligand Inorg. Chem. 2013, 52, 16821684.

(52) Renkema, K. B.; Kissin, Y. V.; Goldman, A. S., The Mechanism of Alkane Transfer-Dehydrogenation Catalyzed by a Pincer-Ligated Iridium Complex J. Am. Chem. Soc. 2003, 125, 7770-7771.

(53) Fan, L.; Foxman, B. M.; Ozerov, O. V., N-H Cleavage as a Route to Palladium Complexes of a New PNP Pincer Ligand Organometallics 2004, 23, 326-328.

(54) Ozerov, O. V.; Guo, C.; Papkov, V. A.; Foxman, B. M., Facile Oxidative Addition of N-C and N-H Bonds to Monovalent Rhodium and Iridium J. Am. Chem. Soc. 2004, 126, 4792-4793.

(55) Zhou, X.; Malakar, S.; Zhou, T.; Murugesan, S.; Huang, C.; Emge, T. J.; Krogh-Jespersen, K.; Goldman, A. S., Catalytic Alkane Transfer Dehydrogenation by PSP-Pincer-Ligated Ruthenium. Deactivation of an Extremely Reactive Fragment by Formation of Allyl Hydride Complexes ACS Catal. 2019, 9, 4072-4083.

(56) Fang, H.; Choe, Y.-K.; Li, Y.; Shimada, S., Synthesis, Structure, and Reactivity of Hydridoiridium Complexes Bearing a Pincer-Type PSiP Ligand Chem. Asian J. 2011, 6, 2512-2521.

(57) Vlugt and co-workers have reported that the analogous PhPPP proligand reacts with an analogous iridium precursor, $[\operatorname{Ir}(C O D)(\mu-O M e)]_{2}$, to give (PhPPP) Ir(COD); thus elimination of MeOH occurred rather than loss of COD as in the present reaction (ref 51). The ${ }^{\mathrm{Ph} P P P}$ ligand of ( $\left.{ }^{\mathrm{Ph}} \mathrm{PPP}\right) \operatorname{Ir}(\mathrm{COD})$ adopts a facial coordination mode (which is never observed in the present work with $\left.{ }^{\mathrm{tBu} P P P}\right)$. The central phosphorus atom of ( $\left.{ }^{\mathrm{Ph} P P P}\right) \operatorname{Ir}(\mathrm{COD})$ can be protonated with $\left[\mathrm{NH}_{4}\right]\left[\mathrm{PF}_{6}\right]$, reversibly, but the cationic complex $\left[\left({ }^{\mathrm{Ph}} \mathrm{P}^{\mathrm{H}} \mathrm{PP}\right) \operatorname{Ir}(\mathrm{COD})\right][\mathrm{PF} 6]$ does not undergo migration of $\mathrm{H}$ from $\mathrm{P}$ to Ir.

(58) A rhodium analogue of ( $\left.{ }^{\mathrm{tBu}} \mathrm{P}^{\mathrm{H}} \mathrm{PP}\right) \mathrm{IrCl}$ has been reported, ( $\left.{ }^{\mathrm{Pr}} \mathrm{P}^{\mathrm{H}} \mathrm{PP}\right) \mathrm{RhCl}$, and was found not to undergo migration of $\mathrm{H}$ from $\mathrm{P}$ to $\mathrm{Rh}$ (ref 50).

(59) Gottker-Schnetmann, I.; White, P.; Brookhart, M., Iridium Bis(phosphinite) p-XPCP Pincer Complexes: Highly Active Catalysts for the Transfer Dehydrogenation of Alkanes J. Am. Chem. Soc. 2004, 126, 1804 -1811.

(60) Punji, B.; Emge, T. J.; Goldman, A. S., A Highly Stable Adamantyl-Substituted Pincer-Ligated Iridium Catalyst for Alkane Dehydrogenation Organometallics 2010, 29, 2702-2709.

(61) Nawara-Hultzsch, A. J.; Hackenberg, J. D.; Punji, B.; Supplee, C.; Emge, T. J.; Bailey, B. C.; Schrock, R. R.; Brookhart, M.; Goldman, A. S., Rational Design of Highly Active "Hybrid" Phosphine-Phosphinite Pincer Iridium Catalysts for Alkane Metathesis ACS Catal. 2013, 3, 2505-2514.

(62) Fryzuk, M. D.; Joshi, K., Coordinated ligand basicity. Synthesis and reactivity of terminal phosphide complexes of iridium that also contain an amide donor Organometallics 1989, 8, 722-726.

(63) Baker, R. T.; Whitney, J. F.; Wreford, S. S., Characterization and interconversion of metal-phosphorus single and double bonds: bis(cyclopentadienyl)zirconium and -hafnium bis(diorganophosphide) complexes Organometallics 1983, 2, 1049-1051.

(64) Kumar, A.; Zhou, T.; Emge, T. J.; Mironov, O.; Saxton, R. J.; Krogh-Jespersen, K.; Goldman, A. S., Dehydrogenation of $n$-Alkanes by Solid-Phase Molecular Pincer-Iridium Catalysts. High Yields of $\alpha$-Olefin Product J. Am. Chem. Soc. 2015, 137, 9894-9911.

(65) Morales-Morales, D.; Redon, R.; Wang, Z.; Lee, D. W.; Yung, C.; Magnuson, K.; Jensen, C. M., Selective dehydrogenation of alcohols and diols catalyzed by a dihydrido iridium PCP pincer complex Can. J. Chem. 2001, 79, 823-829.

(66) See Supporting Information.

(67) Danopoulos, A. A.; Pugh, D.; Wright Joseph, A., "Pincer" pyridine-dicarbene-iridium complexes: facile C-H activation and unexpected eta2-imidazol-2-ylidene coordination Angew. Chem. Int. Ed. Engl. 2008, 47, 9765-9767.

(68) Millard, M. D.; Moore, C. E.; Rheingold, A. L.; Figueroa, J. S., Four-Coordinate Iridium(I) Monohydrides: Reversible Dinitrogen Binding, Bond Activations, and Deprotonations J. Am. Chem. Soc. 2010, 132, 8921-8923. (69) Feller, M.; Gellrich, U.; Anaby, A.; Diskin-Posner, Y.; Milstein, D., Reductive Cleavage of $\mathrm{CO}_{2}$ by Metal-LigandCooperation Mediated by an Iridium Pincer Complex J. Am. Chem. Soc. 2016, 138, 6445-6454.

(70) While we did not find any non-aromatic solvent suitable for the reaction to give ( ${ }^{\text {BBupH}} \mathrm{PP}$ ) IrH , it was repeated in benzene- $d_{6}$, toluene- $d_{8}$, and $p$-xylene- $d_{10}$. No significant difference in chemical shifts resulted, arguing against the possibility that the very downfield shift of the hydride was in any way related to ring current due to the aromatic solvent or a reaction with the solvent. 
(71) Chisholm, M. H.; Eichhorn, B. W.; Huffman, J. C., Reaction between bis(benzyl)tetraisopropoxyditungsten(W $\equiv \mathrm{W})$ and but-2-yne: $\mathrm{W}_{2}\left(\mathrm{CH}_{2} \mathrm{Ph}\right)_{2}\left(\mathrm{OPr}^{\mathrm{i}}\right)_{4}\left(\eta^{2}-\mathrm{C}_{2} \mathrm{Me}_{2}\right)_{2}$ and $\mathrm{W}_{2}(\mathrm{H})\left(\mathrm{OPr}^{\mathrm{i}}\right)_{4}(\mu-\mathrm{CPh})\left(\mu-\mathrm{C}_{4} \mathrm{Me}_{4}\right)$. A terminal metal hydride with a ${ }^{1} \mathrm{H}$ n.m.r. resonance 20 p.p.m. downfield of $\mathrm{Me}_{4} \mathrm{Si}$ J. Chem. Soc., Chem. Commun. 1985, 861-863.

(72) Figueroa, J. S.; Cummins, C. C., The niobaziridine-hydride functional group: synthesis and divergent reactivity J. Am. Chem. Soc. 2003, 125, 4020-4021.

(73) Caffyn, A. J. M.; Feng, S. G.; Dierdorf, A.; Gamble, A. S.; Eldredge, P. A.; Vossen, M. R.; White, P. S.; Templeton, J. L., Unusual proton NMR properties of tungsten(II) tris(pyrazolyl)borate hydride complexes Organometallics 2002, 10, 2842-2848.

(74) Haller, L. J.; Mas-Marza, E.; Moreno, A.; Lowe, J. P.; Macgregor, S. A.; Mahon, M. F.; Pregosin, P. S.; Whittlesey, M. K., Formation of $\left[\mathrm{Ru}(\mathrm{NHC})_{4}\left(\mathrm{eta}(2)-\mathrm{O}_{2}\right) \mathrm{H}\right]^{+}$: an unusual, high frequency hydride chemical shift and facile, reversible coordination of $\mathrm{O}_{2} \mathrm{~J}$. Am. Chem. Soc. 2009, 131, 9618-9619.

(75) Haller, L. J.; Mas-Marza, E.; Cybulski, M. K.; Sanguramath, R. A.; Macgregor, S. A.; Mahon, M. F.; Raynaud, C.; Russell, C. A.; Whittlesey, M. K., Computation provides chemical insight into the diverse hydride NMR chemical shifts of $\left[\mathrm{Ru}(\mathrm{NHC})_{4}(\mathrm{~L}) \mathrm{H}\right](0 /+)$ species $\left(\mathrm{NHC}=\mathrm{N}\right.$-heterocyclic carbene; $\mathrm{L}=$ vacant, $\mathrm{H}_{2}, \mathrm{~N}_{2}, \mathrm{CO}, \mathrm{MeCN}, \mathrm{O}_{2}, \mathrm{P}_{4}, \mathrm{SO}_{2}, \mathrm{H}(-)$, $\mathrm{F}(-)$ and $\mathrm{Cl}(-))$ and their $\left[\mathrm{Ru}\left(\mathrm{R}_{2} \mathrm{PCH}_{2} \mathrm{CH}_{2} \mathrm{PR}_{2}\right)_{2}(\mathrm{~L}) \mathrm{H}\right](+)$ congeners Dalton Trans. 2017, 46, 2861-2873.

(76) Artero, V.; Chavarot-Kerlidou, M.; Fontecave, M., Splitting water with cobalt Angew. Chem., Intl. Ed. 2011, 50, 7238-7266.

(77) DFT-ZORA calculations reproduce the downfield shift, the origin of which is currently under investigation. $C$. Raynaud, O. Eisenstein; personal communication.

(78) The only other example, to our knowledge, of MLC interconversion between an iridium monohydride and dihydride also gives an observable equilibrium (ref 69).

(79) Huang and co-workers have recently reported a series of PCP-type catalysts, bearing one $\mathrm{N}$ and one $\mathrm{O}$ atom as linkers. These show activity somewhat greater than that of ( ${ }^{\mathrm{iPr} P C P}$ )Ir for COA/TBE transfer-dehydrogenation, by a factor of ca. 3, and are likewise very active for n-alkane/TBE transfer-dehydrogenation (ref 80). The most active catalysts previously reported for $n$-alkane/TBE transfer-dehydrogenation, to our knowledge, were those reported by Bézier and Brookhart (ref 81 ), based on the PC(sp3)P triptycene pincer complexes developed by Gelman (refs 82 and 83).

(80) Zhang, X.; Wu, S.-B.; Leng, X.; Chung, L. W.; Liu, G.; Huang, Z., N-Bridged Pincer Iridium Complexes for Highly Efficient Alkane Dehydrogenation and the Relevant Linker Effects ACS Catal. 2020, 10, 6475-6487.

(81) Bezier, D.; Brookhart, M., Applications of PC(sp $\left.{ }^{3}\right)$ P Iridium Complexes in Transfer Dehydrogenation of Alkanes ACS Catal. 2014, 4, 3411-3420.

(82) Azerraf, C.; Gelman, D., Exploring the reactivity of $C\left(\mathrm{sp}^{3}\right)$-cyclometalated IrIII compounds in hydrogen transfer reactions Chem.-Eur. J. 2008, 14, 10364-10368.

(83) Azerraf, C.; Gelman, D., New Shapes of PC(sp⿳3 $\left.{ }^{3}\right)$ P Pincer Complexes Organometallics 2009, 28, 6578-6584.

(84) Biswas, S.; Blessent, M. J.; Gordon, B. M.; Zhou, T.; Malakar, S.; Wang, D. Y.; Krogh-Jespersen, K.; Goldman, A. S., Origin of Regioselectivity in the Dehydrogenation of Alkanes by Pincer-Iridium Complexes: A Combined Experimental and Computational Study ACS Catal. 2021, 11, 12038-12051.

(85) (a) Nawaz, Z. "Light alkane dehydrogenation to light olefin technologies: a comprehensive review" Rev. Chem. Eng. 2015, 31, 413-436. (b) Hu, Z.-P.; Yang, D.; Wang, Z.; Yuan, Z.-Y. "State-of-the-art catalysts for direct dehydrogenation of propane to propylene" Chin. J. Catal. 2019, 40, 1233-1254. (c) Otroshchenko, T.; Jiang, G.; Kondratenko, V. A.; Rodemerck, U.; Kondratenko, E. V. "Current status and perspectives in oxidative, non-oxidative and $\mathrm{CO}_{2}$-mediated dehydrogenation of propane and isobutane over metal oxide catalysts" Chem. Soc. Rev. 2021, 50, 473-527. (d) Chen, S.; Chang, X.; Sun, G.; Zhang, T.; Xu, Y.; Wang, Y.; Pei, C.; Gong, J. "Propane dehydrogenation: catalyst development, new chemistry, and emerging technologies" Chem. Soc. Rev. 2021, 50, 3315-3354. (e) Jiang, X.; Sharma, L.; Fung, V.; Park, S. J.; Jones, C. W.; Sumpter, B. G.; Baltrusaitis, J.; Wu, Z. "Oxidative Dehydrogenation of Propane to Propylene with Soft Oxidants via Heterogeneous Catalysis" ACS Catal. 2021, 11, 2182-2234. (f) Li, C.; Wang, G. "Dehydrogenation of light alkanes to mono-olefins" Chem. Soc. Rev. 2021, 50, 4359-4381. (g) Dai, Y.; Gao, X.; Wang, Q.; Wan, X.; Zhou, C.; Yang, Y. "Recent progress in heterogeneous metal and metal oxide catalysts for direct dehydrogenation of ethane and propane" Chem. Soc. Rev. 2021, 50, 55905630 .

(86) Scriban, C.; Glueck, D. S.; DiPasquale, A. G.; Rheingold, A. L., Chiral Platinum Duphos Terminal Phosphido Complexes: Synthesis, Structure, Phosphido Transfer, and Ligand Behavior Organometallics 2006, 25, 5435-5448.

(87) Falivene, L.; Cao, Z.; Petta, A.; Serra, L.; Poater, A.; Oliva, R.; Scarano, V.; Cavallo, L., Towards the online computer-aided design of catalytic pockets Nat. Chem. 2019, 11, 872-879. 
(88) Riehl, J. F.; Jean, Y.; Eisenstein, O.; Pelissier, M., Theoretical study of the structures of electron-deficient $\mathrm{d}^{6}$ $\mathrm{ML}_{5}$ complexes. Importance of a pi-donating ligand Organometallics 1992, 11, 729-737.

(89) For examples of low temperature alkane dehydrogenation, but at much slower rates or not catalytic, see: (a) McKay, A. I.; Bukvic, A. J.; Tegner, B. E.; Burnage, A. L.; Martinez-Martinez, A. J.; Rees, N. H.; Macgregor, S. A.; Weller, A. S., Room Temperature Acceptorless Alkane Dehydrogenation from Molecular $\sigma$-Alkane Complexes. J. Am. Chem. Soc. 2019, 141, 11700-11712. (b) Solowey, D. P.; Mane, M. V.; Kurogi, T.; Carroll, P. J.; Manor, B. C.; Baik, M.-H.; Mindiola, D. J., A new and selective cycle for dehydrogenation of linear and cyclic alkanes under mild conditions using a base metal. Nat. Chem. 2017, 9, 1126-1132. (c) Crestani, M. G.; Hickey, A. K.; Gao, X.; Pinter, B.; Cavaliere, V. N.; Ito, J.-I.; Chen, C.-H.; Mindiola, D. J., Room Temperature Dehydrogenation of Ethane, Propane, Linear Alkanes C4-C8, and Some Cyclic Alkanes by Titanium-Carbon Multiple Bonds. J. Am. Chem. Soc. 2013, 135, 14754-14767. 
Table of Contents Graphic

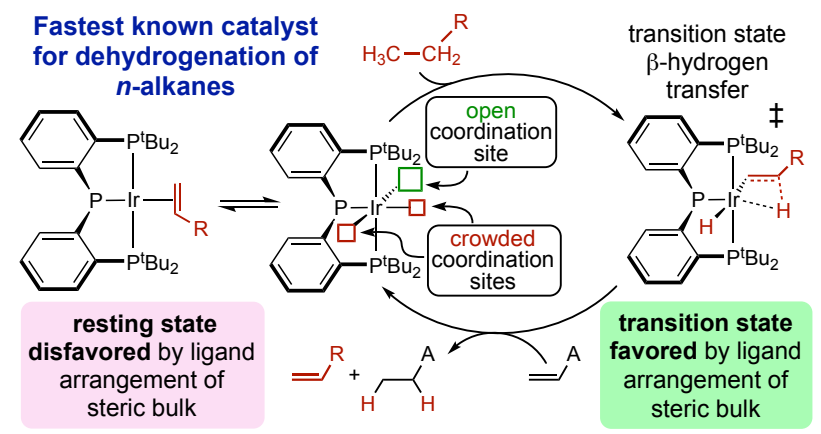

